\title{
Ferroelectric substrate effects on the magnetism, magnetotransport, and electroresistance of $\mathrm{La}_{0.7} \mathrm{Ca}_{0.3} \mathrm{MnO}_{3}$ thin films on $\mathrm{BaTiO}_{3}$
}

\author{
A. Alberca, ${ }^{1,3}$ C. Munuera, ${ }^{1,3}$ J. Tornos,,${ }^{2,3}$ F. J. Mompean,,${ }^{1,3}$ N. Biskup,,${ }^{1,2}$ A. Ruiz, ${ }^{1}$ N. M. Nemes, ${ }^{2,3}$ \\ A. de Andres, ${ }^{1,3}$ C. León, ${ }^{2,3}$ J. Santamaría, ${ }^{2,3}$ and M. García-Hernández ${ }^{1,3}$ \\ ${ }^{1}$ Instituto de Ciencia de Materiales de Madrid, Consejo Superior de Investigaciones Científicas, \\ Sor Juana Inés de la Cruz, 3, ES-28049 Madrid, Spain \\ ${ }^{2}$ GFMC, Departamento de Física Aplicada III, Campus Moncloa, Universidad Complutense Madrid, ES-28040 Madrid, Spain \\ ${ }^{3}$ Laboratorio de Heteroestructuras con aplicación en Spintronica, Unidad Asociada CSIC/Universidad Complutense Madrid, \\ Sor Juana Inés de la Cruz, 3, ES-28049 Madrid, Spain
}

(Received 3 August 2012; revised manuscript received 21 September 2012; published 24 October 2012)

\begin{abstract}
$\mathrm{La}_{0.7} \mathrm{Ca}_{0.3} \mathrm{MnO}_{3}$ optimally doped epitaxial films were grown on ferroelectric $\mathrm{BaTiO}_{3}$ substrates. Electronic transport (magnetoresistance and electroresistance) and magnetic properties showed important anomalies in the temperature interval between 60 and $150 \mathrm{~K}$, below the metal-insulator transition. Scanning probe microscopy revealed changes in $\mathrm{BaTiO}_{3}$ surface morphology at those temperatures. $\mathrm{La}_{0.7} \mathrm{Ca}_{0.3} \mathrm{MnO}_{3}$ thickness is a critical factor: 120 - $\AA$-thick films showed large anomalies sensitive to electric poling of the $\mathrm{BaTiO}_{3}$, whereas the behavior of 150 - $\AA$-thick films is closer to that of the reference $\mathrm{La}_{0.7} \mathrm{Ca}_{0.3} \mathrm{MnO}_{3}$ samples grown on $\mathrm{SrTiO}_{3}$. We propose that, through inhomogenous strain and electric polarization effects, the ferroelectric substrate induces an inhomogenous spin distribution in the magnetic layer. This would imply the coexistence of in-plane and out-of-plane ferromagnetic patches in $\mathrm{La}_{0.7} \mathrm{Ca}_{0.3} \mathrm{MnO}_{3}$, possibly interspersed with antiferromagnetic regions, as it has recently been theoretically predicted. Substrate poling effects are investigated, and a magnetoelectric coupling is demonstrated.
\end{abstract}

DOI: 10.1103/PhysRevB.86.144416

PACS number(s): 75.25.-j, 75.70.-i, 77.55.Px

\section{INTRODUCTION}

Most recent developments in oxide-based spintronics involve multiferroic materials and/or multiferroic heterostructures. ${ }^{1,2}$ However, the few known natural multiferroics have drawbacks. Those, such as $\mathrm{BiFeO}_{3}$, with high electric polarization present weak coupling between the electronic and magnetic degrees of freedom. High magnetoelectric coupling comes with low electric polarizations arising with magnetic ordering, as in $\mathrm{TbMnO}_{3}$ and $\mathrm{TbMnO}_{5}$ (Ref. 3). Artificial multiferroic heterostructures can combine optimal ferromagnetic (FM) and ferroelectric properties, especially for spin-dependent tunnel devices with functional oxide barriers. Given the excellent epitaxial growth of perovskite thin films, devices combining ferroelectric $\mathrm{BaTiO}_{3}$ and FM manganites, e.g. $\mathrm{La}_{0.7} \mathrm{Ca}_{0.3} \mathrm{MnO}_{3}$ or $\mathrm{La}_{0.7} \mathrm{Sr}_{0.3} \mathrm{MnO}_{3}$ are very attractive. ${ }^{4}$ These complex oxides are prone to phase separation, and their interface with ferroelectrics has been shown to exhibit a rich phenomenology, both experimentally ${ }^{5}$ (including a novel proposal for a metal-insulator transition near the interface due to electrostatic doping ${ }^{6}$ ) and theoretically. ${ }^{7-9}$

Substrate-induced strain is propagated to epitaxially grown heterostructures of piezoelectrics and ferromagnets, such as $\mathrm{BaTiO}_{3}$ and manganites. ${ }^{10}$ As a result, the strain-sensitive magnetic/charge/orbital states of the manganite can be altered through the piezoelectric with an electric field or conversely the polarization/strain of the piezoelectric may change by acting on the magnetic state of the ferromagnet. ${ }^{11}$

Numerous studies ${ }^{12-17}$ recognize the complexity and the interest of bulk $\mathrm{BaTiO}_{3}$ as a substrate. These features result from the occurrence of two structural phase transitions below room temperature, implying changes in the magnitude and direction of the spontaneous electrical polarization vector within the unit cell. Thus, varying degrees of strain and electric field are exerted on the thin layers, and the way is open to further control them by application of an external electric field to the substrates. The discontinuities in resistivity and low field magnetization of 500- $\AA \mathrm{La}_{0.7} \mathrm{Sr}_{0.3} \mathrm{MnO}_{3}$ films on $\mathrm{BaTiO}_{3}$ due to the substrate structural phase transitions have been studied in Ref. 12. Converse magnetoelectric effects with coefficients as high as $2.3 \times 10^{-7} \mathrm{~s} / \mathrm{m}$ have been reported for $400-\AA$ films of $\mathrm{La}_{0.7} \mathrm{Sr}_{0.3} \mathrm{MnO}_{3}$ on $\mathrm{BaTiO}_{3}$ in Ref. 11 . Recently, we have also explored the magnetic behavior of a very thin layer of $\mathrm{La}_{0.7} \mathrm{Ca}_{0.3} \mathrm{MnO}_{3}$ on poled $\mathrm{BaTiO}_{3}$ (Ref. 18), a system with a narrower bandwidth than $\mathrm{La}_{0.7} \mathrm{Sr}_{0.3} \mathrm{MnO}_{3}$ (Ref. 19) and enhanced tendency to microphase separation where the presence of an antiferromagnetic (AFM) insulating state is more likely. ${ }^{20}$

Our previous study ${ }^{18}$ focused on the appearance of anomalous magnetic hysteresis loops, so called Matteucci cycles, in a set of thin $\mathrm{La}_{0.7} \mathrm{Ca}_{0.3} \mathrm{MnO}_{3} / \mathrm{BaTiO}_{3}$ films. We interpreted these results in terms of the existence of two populations of magnetic moments: a majority which aligns in plane with a magnetic field and a minority, whose relative abundance shows temperature dependence with a maximum near $120 \mathrm{~K}$, which lies out of plane. Through magnetoelastic effects, this anomalous magnetic behavior would result from the inhomogeneous strain map created by $\mathrm{BaTiO}_{3}$ surface corrugation due to ferroelectric domains. The coupling between the two magnetic moment populations is expected to severely alter the transport properties of $\mathrm{La}_{0.7} \mathrm{Ca}_{0.3} \mathrm{MnO}_{3}$ since the metalinsulator (MI) transition, accompanying the paramagnetic-toFM transition, is percolative in nature. ${ }^{21}$ In addition, substrate corrugation is expected to introduce new phenomenology related to enhanced phase separation at the micron length scale. 
Here, we explore the temperature dependence of the magnetization and transport properties (resistivity, magnetoresistance, electroresistance) of thin $\mathrm{La}_{0.7} \mathrm{Ca}_{0.3} \mathrm{MnO}_{3}$ films on ferroelectric $\mathrm{BaTiO}_{3}$ and compare them with those of thicker $\mathrm{La}_{0.7} \mathrm{Ca}_{0.3} \mathrm{MnO}_{3} / \mathrm{BaTiO}_{3}$ films and $\mathrm{La}_{0.7} \mathrm{Ca}_{0.3} \mathrm{MnO}_{3}$ grown on $\mathrm{SrTiO}_{3}$. We show that the structurally epitaxial thin $\mathrm{La}_{0.7} \mathrm{Ca}_{0.3} \mathrm{MnO}_{3} / \mathrm{BaTiO}_{3}$ films become electrically (and magnetically) granular and exhibit behavior not compatible with uniform long-range FM order. We correlate the observed magnetic and transport behavior with temperature-dependent surface morphology changes of $\mathrm{BaTiO}_{3}$ in the rhombohedral (R) phase. We propose that a fine-grained secondary corrugation, developing in the $\mathrm{R}$ phase of $\mathrm{BaTiO}_{3}$ may induce changes in the magnetic anisotropy map or enhance the tendency to phase segregation in the $\mathrm{La}_{0.7} \mathrm{Ca}_{0.3} \mathrm{MnO}_{3} / \mathrm{BaTiO}_{3}$ interface. The effect of substrate poling on the electronic transport is also studied, evidencing magnetoelectric coupling: variations in the ferroelectric domain pattern in $\mathrm{BaTiO}_{3}$ are responsible for changes in the strain pattern experienced by the magnetic layer as well as for changes in the charge distribution at the interface. Both effects induce substantial changes in the magnetic and electric behavior of $\mathrm{La}_{0.7} \mathrm{Ca}_{0.3} \mathrm{MnO}_{3}$. Inhomogeneous doping due to charge accumulation at the interface of $\mathrm{La}_{0.7} \mathrm{Ca}_{0.3} \mathrm{MnO}_{3}$ could even enhance AFM correlations in $\mathrm{La}_{0.7} \mathrm{Ca}_{0.3} \mathrm{MnO}_{3}$, in agreement with recent predictions, ${ }^{7-9}$ which would increase the resistance of the layer.

\section{EXPERIMENTAL}

Thin films were prepared on unpoled $\mathrm{BaTiO}_{3}(001)$ and $\mathrm{SrTiO}_{3}(001)\left(5 \times 5 \times 1 \mathrm{~mm}^{3}\right)$ substrates by sputtering with a highly oxidizing plasma (3.4 mbar oxygen atmosphere) at temperatures $(1173 \mathrm{~K})$, well above the $\mathrm{BaTiO}_{3}$ ferroelectric Curie point. We will refer to these samples as $\mathrm{La}_{0.7} \mathrm{Ca}_{0.3} \mathrm{MnO}_{3} / \mathrm{BaTiO}_{3}$ and $\mathrm{La}_{0.7} \mathrm{Ca}_{0.3} \mathrm{MnO}_{3} / \mathrm{SrTiO}_{3}$, respectively. The deposition rate was very slow (around $1 \mathrm{~nm} / \mathrm{min}$ ) and strict annealing ( $1 \mathrm{~h}$ at $823 \mathrm{~K}$ in 1 bar of oxygen) and cooling $(20 \mathrm{~K} / \mathrm{min})$ procedures were followed. Several highly comparable samples of $\mathrm{La}_{0.7} \mathrm{Ca}_{0.3} \mathrm{MnO}_{3} / \mathrm{BaTiO}_{3}$ were grown using the same growth conditions, with 120-, 150-, and $240-\AA$ thickness. For this study, control samples of $\mathrm{La}_{0.7} \mathrm{Ca}_{0.3} \mathrm{MnO}_{3} / \mathrm{SrTiO}_{3}$ with $120-\AA$ thickness, grown along with $\mathrm{La}_{0.7} \mathrm{Ca}_{0.3} \mathrm{MnO}_{3} / \mathrm{BaTiO}_{3}$, were studied in detail for comparison. The properties of $\mathrm{La}_{0.7} \mathrm{Ca}_{0.3} \mathrm{MnO}_{3} / \mathrm{SrTiO}_{3}$ samples grown under the same conditions reported in this paper are detailed in Ref. 22.

The $\mathrm{La}_{0.7} \mathrm{Ca}_{0.3} \mathrm{MnO}_{3} / \mathrm{BaTiO}_{3}$ samples were exposed to various thermal and electrical treatments during the experiments. When required, sample poling was effected ex situ at room temperature by repeatedly running a ferroelectric switching cycle on the $\mathrm{BaTiO}_{3}$ substrate by applying a sufficiently large quasi-dc electric field (up to $500 \mathrm{kV} / \mathrm{m}$ ) between the $\mathrm{La}_{0.7} \mathrm{Ca}_{0.3} \mathrm{MnO}_{3}$ film and a silver electrode on the back side. The typical switching field at room temperature was found to be around $70-80 \mathrm{kV} / \mathrm{m}$. Later on, each sample was thermally cycled to low temperature during the electrical transport and magnetization measurements. Thermal and electrical fatigue eventually leads to cracking and loss of reproducibility in the measurements, at which point the damaged samples were discarded.
$\mathrm{X}$-ray diffraction and reflectometry characterization of the $\mathrm{La}_{0.7} \mathrm{Ca}_{0.3} \mathrm{MnO}_{3} / \mathrm{BaTiO}_{3}$ and $\mathrm{La}_{0.7} \mathrm{Ca}_{0.3} \mathrm{MnO}_{3} / \mathrm{SrTiO}_{3}$ were performed on a Bruker D8 4-circle diffractometer $\left(\mathrm{Cu} \mathrm{K} \mathrm{K}_{\alpha 1}\right.$ radiation) equipped with a LynxEye position sensitive detector. Also, $\mathrm{BaTiO}_{3}$ substrates were studied at low temperatures using a bespoke cryogenic sample holder.

Temperature-dependent surface morphology was studied with scanning probe microscopy (SPM). Low-temperature SPM measurements were performed with a commercial system from Nanomagnetics Instruments and silicon cantilevers from BudgetSensors (Multi75Al-G). Amplitude modulation mode was used to investigate $\mathrm{BaTiO}_{3}$ morphology as the temperature was decreased from 300 to $100 \mathrm{~K}$. Topographic images were recorded (at a rate of $30 \mathrm{~min} /$ image) every $30 \mathrm{~K}$ (thermal stabilization periods of $60 \mathrm{~min}$ were allowed at each temperature) following the same area throughout the whole temperature range.

The temperature- and magnetic-field-dependent magnetization were measured using a vibrating sample magnetometer (VSM) or, alternatively, a superconducting quantum interference device (SQUID) magnetometer, both from Quantum Design, and equipped with 9- and 5-T coils, respectively. In the VSM measurements, 2-mm vibration amplitude at $40 \mathrm{~Hz}$ was used, whereas in SQUID magnetometry, the scan length was $3 \mathrm{~cm}$. The temperature-dependent magnetization was measured following zero field cooling (ZFC, 10- and 100-mT measuring fields) and field cooling (FC, 10- and 100-mT cooling and measuring fields) protocols, the field being always in the plane of the $\mathrm{La}_{0.7} \mathrm{Ca}_{0.3} \mathrm{MnO}_{3}$ film. The magnetization is reported as magnetic moment per $\mathrm{Mn}$ ion of the $\mathrm{La}_{0.7} \mathrm{Ca}_{0.3} \mathrm{MnO}_{3}$ films in Bohr magnetons $\left(\mu_{\mathrm{B}} / \mathrm{Mn}\right)$. The bulk saturation value in $\mathrm{La}_{0.7} \mathrm{Ca}_{0.3} \mathrm{MnO}_{3}$ is $3.7 \mu_{\mathrm{B}} / \mathrm{Mn}$. Magnetization hysteresis loops were recorded at various temperatures, after cooling to $10 \mathrm{~K}$ in $1 \mathrm{~T}$, between $\pm 1 \mathrm{~T}$ with a slow sweep rate of 1-2 $\mathrm{mT} / \mathrm{s}$. The diamagnetic contribution of the substrates was subtracted by estimating the high field linear dependence above the saturating field of $\mathrm{La}_{0.7} \mathrm{Ca}_{0.3} \mathrm{MnO}_{3}$.

Electronic transport of the samples was characterized by measuring the resistance of the film in plane with the van der Pauw method, with contacts placed in the four corners of the square shaped samples. Voltage was measured with alternating direction of the dc excitation current to eliminate thermoelectric voltages. Furthermore, readings were taken quasisimultaneously, with the excitation current passed along one or the other perpendicular edges of the sample, parallel or perpendicular to the applied magnetic field. Magnetoresistance (MR) was calculated by normalizing to the zero-field resistance. Electroresistance (ER) was calculated from the nonlinear $I$ - $V$ curves. In order to discern and eliminate Joule-heating effects, at a few temperatures, pulsed $I$ - $V$ curves were recorded.

\section{RESULTS}

\section{A. Structure and morphology}

We have previously ${ }^{18}$ reported structural results as a function of temperature for $\mathrm{La}_{0.7} \mathrm{Ca}_{0.3} \mathrm{MnO}_{3} / \mathrm{BaTiO}_{3}$ samples exhibiting exotic Matteucci-like behavior obtained from coplanar and grazing incidence x-ray diffraction (GIXD) synchrotron studies. We found good epitaxial adherence of $\mathrm{La}_{0.7} \mathrm{Ca}_{0.3} \mathrm{MnO}_{3}$ to $\mathrm{BaTiO}_{3}$ in spite of the complexity of the 


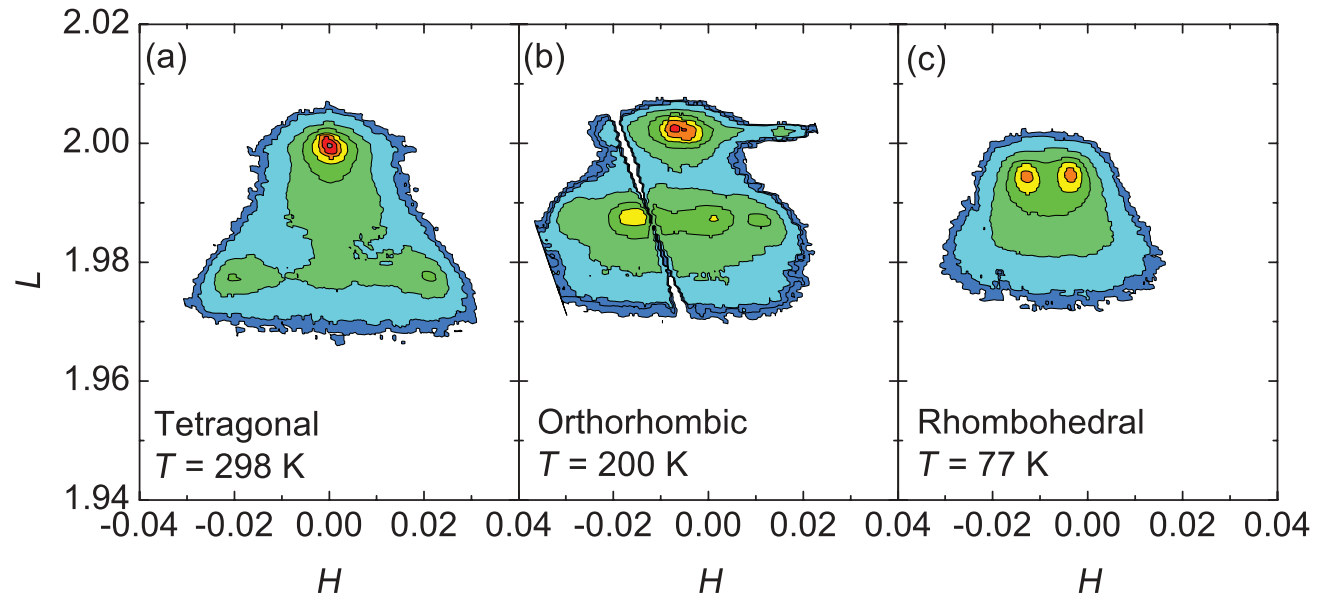

FIG. 1. (Color online) Reciprocal space maps of an unpoled $\mathrm{BaTiO}_{3}$ substrate cooled from (a) the tetragonal phase at room temperature to (b) the orthorhombic phase at $200 \mathrm{~K}$, and finally to (c) the R phase at $77 \mathrm{~K}$. The maps correspond to the region near (002) $+(200)$ in the tetragonal phase and were taken by reference to a tetragonal (200) reflection.

substrate, with $\mathrm{La}_{0.7} \mathrm{Ca}_{0.3} \mathrm{MnO}_{3}$ lattice constants following consistently the changes experienced by $\mathrm{BaTiO}_{3}$ at low temperature. In this paper, we report results obtained at low temperatures by $\mathrm{x}$-ray diffraction and SPM on unpoled $\mathrm{BaTiO}_{3}$ substrates. At room temperature, we extend our structural characterization with measurements of reciprocal space maps of coplanar symmetric and asymmetric reflections on $\mathrm{La}_{0.7} \mathrm{Ca}_{0.3} \mathrm{MnO}_{3} / \mathrm{BaTiO}_{3}$ and $\mathrm{La}_{0.7} \mathrm{Ca}_{0.3} \mathrm{MnO}_{3} / \mathrm{SrTiO}_{3}$.

\section{Evolution with temperature of the ferroelectric domains and surface morphology of $\mathrm{BaTiO}_{3}$}

Although some debate still exists on the crystallographic description of the low-temperature phases of $\mathrm{BaTiO}_{3}$ (Refs. 23 and 24), in this paper, we adopt the standard description as given, for example, in Ref. 25, which is closer to our observations. $\mathrm{BaTiO}_{3}$ is cubic and paraelectric above $393 \mathrm{~K}$. At room temperature, the tetragonal lattice parameters of $\mathrm{BaTiO}_{3}$ are $a=b=3.994 \AA$ and $c=4.038 \AA$. Upon cooling, at $T=295 \mathrm{~K}, \mathrm{BaTiO}_{3}$ undergoes a tetragonal $(\mathrm{T})$ to orthorhombic $(\mathrm{O})$ transition, and at $T=183 \mathrm{~K}$, the system becomes R. The pattern of ferroelectric domains generated by the electric and elastic balance is modified by thermal cycles and/or poling, resulting in samples composed of misoriented twins. Thus, surface morphology changes and different corrugations are expected in all $\mathrm{BaTiO}_{3}$ ferroelectric phases. We observe that repeated thermal or electrical poling eventually leads to fracture of our samples, which has been interpreted on the basis of local defect symmetry failing to adjust to long-range crystal symmetry. ${ }^{26,27}$

Figure 1 illustrates the evolution with temperature of the reflections arising from the ferroelectric domains of an unpoled $\mathrm{BaTiO}_{3}$ substrate. Figure 1(a) corresponds to a reciprocal space map at room temperature near the tetragonal $(200)+(002)$ region. In this case, the sample was aligned with the reflection from the $a$ domain $^{28}$ (out-of-plane lattice parameter: $3.995 \AA$ ), which appears as an intense peak near $L=2$. Weaker peaks from $c$ domains are visible for $L=1.976$, the maximum misorientation among them being $1.2^{\circ}$. Figure $1(\mathrm{~b})$ shows the domain pattern in the orthorhombic phase taken at $200 \mathrm{~K}$.
The pattern resembles that observed in the tetragonal phase but with misorientations slightly smaller $\left(0.5^{\circ}\right.$ for the value corresponding to pseudo- $c$ and pseudo- $a$ domains). Finally, in Fig. 1(c), taken at $77 \mathrm{~K}$ in the $\mathrm{R}$ phase, only two peaks of almost equal intensity are apparent. Their relative misorientation is $0.27^{\circ}$. Table I summarizes these results, together with the measured lattice parameters, which are in good agreement with the high-resolution neutron, low-strain, powder diffraction results from Ref. 25 .

$\mathrm{BaTiO}_{3}$ substrates exhibit great variability in their domain patterns due to the strong influence of thermal and electrical history. A representative unpoled (001) single crystal $\mathrm{BaTiO}_{3}$ substrate was studied at various temperatures, upon cooling, with SPM in a low-pressure (10 Torr) He atmosphere. Topographic images of the same area are shown in Fig. 2 for selected temperatures at $300 \mathrm{~K}$ [Fig. 2(a)], $270 \mathrm{~K}$ [Fig. 2(b)], $180 \mathrm{~K}$ [Fig. 2(c)], and $100 \mathrm{~K}$ [Fig. 2(d)]. To better highlight possible changes in morphology with temperature, line profiles are compared in pairs in Figs. 2(e)-2(g). In order to avoid image processing artifacts, only global plane subtraction was applied prior to profile measurement. The corresponding morphology for the T, O, and R phases is shown in Figs. 2(a)-2(c). The surface morphology at $100 \mathrm{~K}$ is also presented in Fig. 2(d). In the scanned area, the $\mathrm{BaTiO}_{3}$ surface exhibits, in all ferroelectric phases, a primary corrugation with a characteristic length around $15 \mu \mathrm{m}$ that yields a mean roughness of $7.5 \mathrm{~nm}$ on $50 \times 50 \mu \mathrm{m}^{2}$ areas. This corrugation, explained by the ferroelectric equilibrium conditions prevailing in the $\mathrm{T}$ phase, ${ }^{28}$ dominates the landscape, but some rippling of the slopes is also apparent. From 300 to $180 \mathrm{~K}$, only minor

TABLE I. Experimental values for the lattice parameters and $a-c$ domain misorientation angles of an unpoled $\mathrm{BaTiO}_{3}$ substrate as a function of temperature.

\begin{tabular}{llll}
\hline \hline$T(\mathrm{~K})$ & $a(\AA)$ & $c(\AA)$ & Misorientation angle $\left(^{\circ}\right)$ \\
\hline 300 & 3.995 & 4.038 & 0.6 \\
200 & 4.019 & 3.991 & 0.5 \\
77 & & 4.005 & 0.27 \\
\hline \hline
\end{tabular}



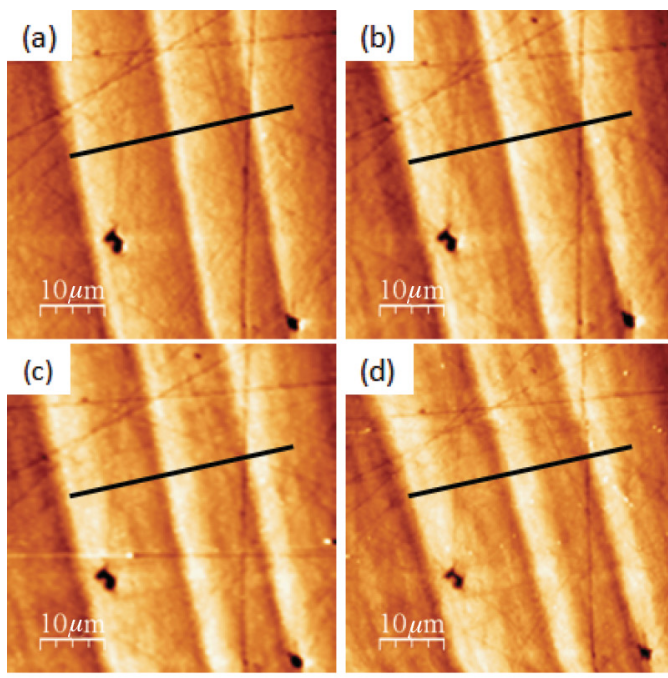

(d)

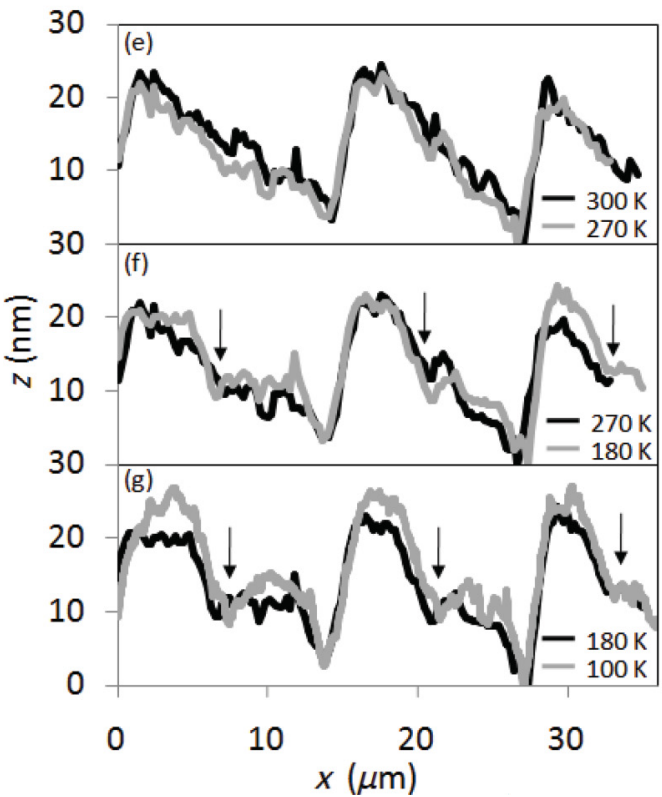

FIG. 2. (Color online) Topography of a $\mathrm{BaTiO}_{3}$ substrate above and below the tetragonal-orthorhombic phase transition at (a) $300 \mathrm{~K}$ and (b) $270 \mathrm{~K}$, in the $\mathrm{R}$ phase at (c) $180 \mathrm{~K}$ and at (d) $100 \mathrm{~K}$. Panels (e)-(g) show a comparison of the line profiles of (a)-(d) in pairs.

changes are observed in the surface morphology corresponding to this dominant corrugation, which translate into very similar profiles for 300 and $270 \mathrm{~K}$ [Fig. 2(e)]. This behavior has also been reported in $\mathrm{BaTiO}_{3}$ (111) samples studied by transmission electron microscopy. ${ }^{29}$ At $180 \mathrm{~K}$, differences are hardly noticeable in the SPM image, but line profiles show subtle deviations from those measured at higher temperatures [Fig. 2(f)]. These differences are marked with black arrows and show the disruption of the primary slope and the formation of a moundlike structure or secondary corrugation, with a characteristic length close to $7.5 \mu \mathrm{m}$, about half of value of the primary corrugation. In view of the variability exhibited by the $\mathrm{BaTiO}_{3}$ substrates, the precise values of the corrugation characteristic lengths should not be understood as general properties of these ferroelectric substrates. The T-O structural phase transition at $295 \mathrm{~K}$ seems to trigger the observed changes
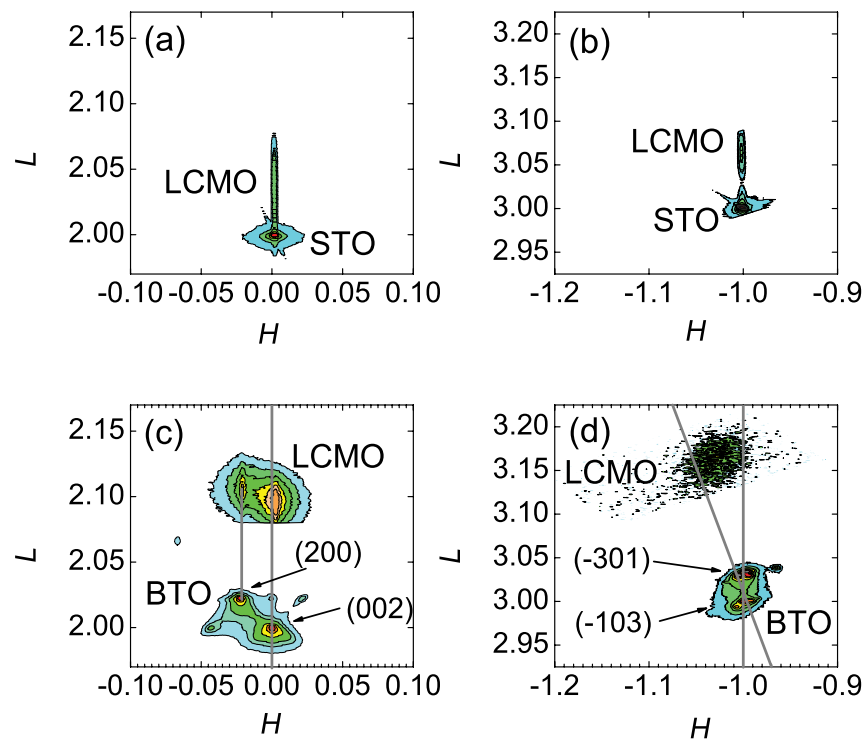

FIG. 3. (Color online) Room temperature coplanar XRD reciprocal space maps around the (002) reflection (left) and the asymmetric ( -103 ) region (right) for: (a) and (b) an $\mathrm{La}_{0.7} \mathrm{Ca}_{0.3} \mathrm{MnO}_{3} / \mathrm{SrTiO}_{3}$ sample, $100 \AA$, and (c) and (d) unpoled $\mathrm{La}_{0.7} \mathrm{Ca}_{0.3} \mathrm{MnO}_{3} / \mathrm{BaTiO}_{3}$ with thickness $120 \AA$. In (d), the vertical (inclined) line represents the $R=0(R=1)$ direction. LCMO stands for $\mathrm{La}_{0.7} \mathrm{Ca}_{0.3} \mathrm{MnO}_{3}$, BTO for $\mathrm{BaTiO}_{3}$ and $\mathrm{STO}$ for $\mathrm{SrTiO}_{3}$.

in surface morphology, but it is below the O-R transition where the secondary corrugation consolidates. No further structural transition is expected on cooling below 183 K. Surprisingly, significant changes in the topographic profiles are measured at $100 \mathrm{~K}$. These are marked in Fig. 2(g) and include height differences of up to $4 \mathrm{~nm}$ (over $2 \mu \mathrm{m}$ ) and the final formation of the secondary corrugation.

\section{X-ray diffraction studies of $\mathrm{La}_{0.7} \mathrm{Ca}_{0.3} \mathrm{MnO}_{3} / \mathrm{SrTi} \mathrm{O}_{3}$ and $\mathrm{La}_{0.7} \mathrm{Ca}_{0.3} \mathrm{MnO}_{3} / \mathrm{BaTiO}_{3}$ at room temperature}

Figure 3 shows reciprocal space maps for a $\mathrm{La}_{0.7} \mathrm{Ca}_{0.3} \mathrm{MnO}_{3} / \mathrm{SrTiO}_{3}$ sample [Figs. 3(a) and 3(b)] and an unpoled $\mathrm{La}_{0.7} \mathrm{Ca}_{0.3} \mathrm{MnO}_{3} / \mathrm{BaTiO}_{3}$ sample [Figs. 3(c) and 3(d)] with 120 - $\AA$ thickness as determined by $\mathrm{x}$-ray reflectometry. At room temperature, $\mathrm{SrTiO}_{3}$ has a cubic perovskite unit cell with parameter $a=3.905 \AA$. $\mathrm{La}_{0.7} \mathrm{Ca}_{0.3} \mathrm{MnO}_{3}$ on $\mathrm{SrTiO}_{3}$ [Fig. 3(a)] is epitaxial with large spatial coherence, as evidenced by the peak width in the $H$ direction. The observed out-of-plane $\mathrm{La}_{0.7} \mathrm{Ca}_{0.3} \mathrm{MnO}_{3}$ lattice parameter is $3.824 \AA$. The in-plane lattice parameter of $\mathrm{La}_{0.7} \mathrm{Ca}_{0.3} \mathrm{MnO}_{3}$ is that of $\mathrm{SrTiO}_{3}$, as obtained from the asymmetric $(-103)$ reflection [Fig. 3(b)]. The degree of relaxation, $R=\left(a_{L}-a_{S}\right) /\left(a_{P}-a_{S}\right)$ with $a_{\mathrm{L}}$ the layer in-plane parameter, $a_{\mathrm{P}}$ the parameter in the bulk, and as the substrate in-plane parameter, is zero for $\mathrm{La}_{0.7} \mathrm{Ca}_{0.3} \mathrm{MnO}_{3} / \mathrm{SrTiO}_{3} . \mathrm{La}_{0.7} \mathrm{Ca}_{0.3} \mathrm{MnO}_{3} / \mathrm{BaTiO}_{3}$ exhibits, by comparison to $\mathrm{La}_{0.7} \mathrm{Ca}_{0.3} \mathrm{MnO}_{3} / \mathrm{SrTiO}_{3}$, more complex reciprocal space maps [Figs. 3(c) and 3(d)]. Figure 3(c) shows two main peaks [labeled (200) and (002)] whose misorientation matches the theoretical value of $90^{\circ}-2$ atan $(a / c)=0.6^{\circ}$ corresponding to $90^{\circ}$ domain walls in the $\mathrm{T}$ phase. ${ }^{28}$ At larger $\mathrm{L}$ values, two $\mathrm{La}_{0.7} \mathrm{Ca}_{0.3} \mathrm{MnO}_{3}$ peaks are visible corresponding to $\mathrm{La}_{0.7} \mathrm{Ca}_{0.3} \mathrm{MnO}_{3}$ on $a$ and $c$ 
ferroelectric $\mathrm{BaTiO}_{3}$ domains. Their out-of-plane parameters are $c=3.834$ and $3.852 \AA$, respectively. This implies a $0.5 \%$ difference in the deviation from the pseudocubic symmetry due to the change in the out-of-plane parameter. From the asymmetric reciprocal space map near $\mathrm{BaTiO}_{3}$ $(-103)+(-301)$ [Fig. 3(d)], we can calculate only a single value for the in-plane parameter, $a=3.915 \AA$, and observe $\mathrm{La}_{0.7} \mathrm{Ca}_{0.3} \mathrm{MnO}_{3}$ on $\mathrm{BaTiO}_{3}$ to be partially relaxed $(R \approx 0.7)$. As-prepared samples show relaxation varying between $R=0.3$ to 0.7 . From the width of the broad $\mathrm{La}_{0.7} \mathrm{Ca}_{0.3} \mathrm{MnO}_{3}$ peaks in the symmetric and asymmetric reflections, we estimate coherence lengths in the out-of-plane direction, $L_{c}=70-95 \AA$. Coherence lengths in the in-plane direction, $L_{\mathrm{a}}$, fall in a broader interval (70-200 $\AA$, depending on the sample) unrelated to any systematic variation of morphological or structural features. At room temperature, $\mathrm{La}_{0.7} \mathrm{Ca}_{0.3} \mathrm{MnO}_{3}$ thin films on $\mathrm{BaTiO}_{3}$ are strained: tensile in-plane and compressive out-of-plane.

\section{B. Magnetism}

$\mathrm{La}_{0.7} \mathrm{Ca}_{0.3} \mathrm{MnO}_{3}$ thin films on $\mathrm{BaTiO}_{3}$ show interesting magnetic properties: the saturation moments $\left(M_{\mathrm{S}}\right)$ of $\mathrm{La}_{0.7} \mathrm{Ca}_{0.3} \mathrm{MnO}_{3} / \mathrm{BaTiO}_{3}$ [Figs. 4(b)-4(d)] are depressed compared to $\mathrm{La}_{0.7} \mathrm{Ca}_{0.3} \mathrm{MnO}_{3} / \mathrm{SrTiO}_{3}$ [Fig. 4(a)], whereas the coercive fields are an order of magnitude larger. ${ }^{18}$ A blocking temperature can be defined below the $\mathrm{O}-\mathrm{R}$ transition in $\mathrm{La}_{0.7} \mathrm{Ca}_{0.3} \mathrm{MnO}_{3} / \mathrm{BaTiO}_{3}$, where the $\mathrm{ZFC}$ magnetization has a maximum, as depicted in Figs. 4(b)-4(d). This magnetic behavior was interpreted as a signature of a granular magnetic system in agreement with the linear temperature dependence of the coercive fields. ${ }^{18}$ Rather conspicuously, some $\mathrm{La}_{0.7} \mathrm{Ca}_{0.3} \mathrm{MnO}_{3} / \mathrm{BaTiO}_{3}$ samples exhibit negative magnetization at low temperature after cooling without applied field, see Fig. 4(c). As expected, both Curie temperature ( $T_{\mathrm{c}}$, see Fig. 4) and $M_{\mathrm{S}}$ (see Fig. 5) increase with sample thickness: $T_{\mathrm{c}}(120 \AA)=180 \mathrm{~K}, T_{\mathrm{c}}(150 \AA)=220 \mathrm{~K}$, and $T_{\mathrm{c}}(240 \AA)=230 \mathrm{~K}$. As previously reported on $\mathrm{La}_{0.7} \mathrm{Sr}_{0.3} \mathrm{MnO}_{3} / \mathrm{BaTiO}_{3}$ (Refs. 11 and 12), hysteretic jumps of the magnetization are detected around the $\mathrm{BaTiO}_{3}$ phase transitions that become smoother in thick films (Fig. 4 insets). The isothermal behavior, depicted in Fig. 5, reveals that thinner samples $(120 \AA)$ have hysteresis cycles with features that resemble Matteucci cycles between 60 and $120 \mathrm{~K}$ (Fig. 4 inset for $M_{\mathrm{s}}$ and $H_{\mathrm{c}}$ vs $T$ ), as previously reported. The magnetization overshoots symmetrically on both branches and involves almost $30 \%$ of the moment. This was interpreted on magnetoelastic grounds as due to the existence of a fraction of moments, near the $\mathrm{La}_{0.7} \mathrm{Ca}_{0.3} \mathrm{MnO}_{3}$ interface with $\mathrm{BaTiO}_{3}$, whose magnetization aligns out of plane with increasing applied magnetic field. The easy axis remains in plane at all temperatures [Fig. 5(a)]. Thicker samples $(150,240 \AA)$ do not exhibit Matteucci-like features, have saturated moments closer to the bulk values, but still show large coercive fields [Fig. 5(c)]. Figure 6 compares for a $120-\AA \mathrm{La}_{0.7} \mathrm{Ca}_{0.3} \mathrm{MnO}_{3} / \mathrm{BaTiO}_{3}$ the hysteresis loops recorded at $190 \mathrm{~K}$ after either cooling from $300 \mathrm{~K}$ in the $\mathrm{BaTiO}_{3} \mathrm{O}$ phase or warming from $10 \mathrm{~K}$ in the $\mathrm{R}$ phase. Even though the magnetic moment is higher in the $\mathrm{R}$ phase, the coercive fields are larger in the $\mathrm{O}$ phase, indicating

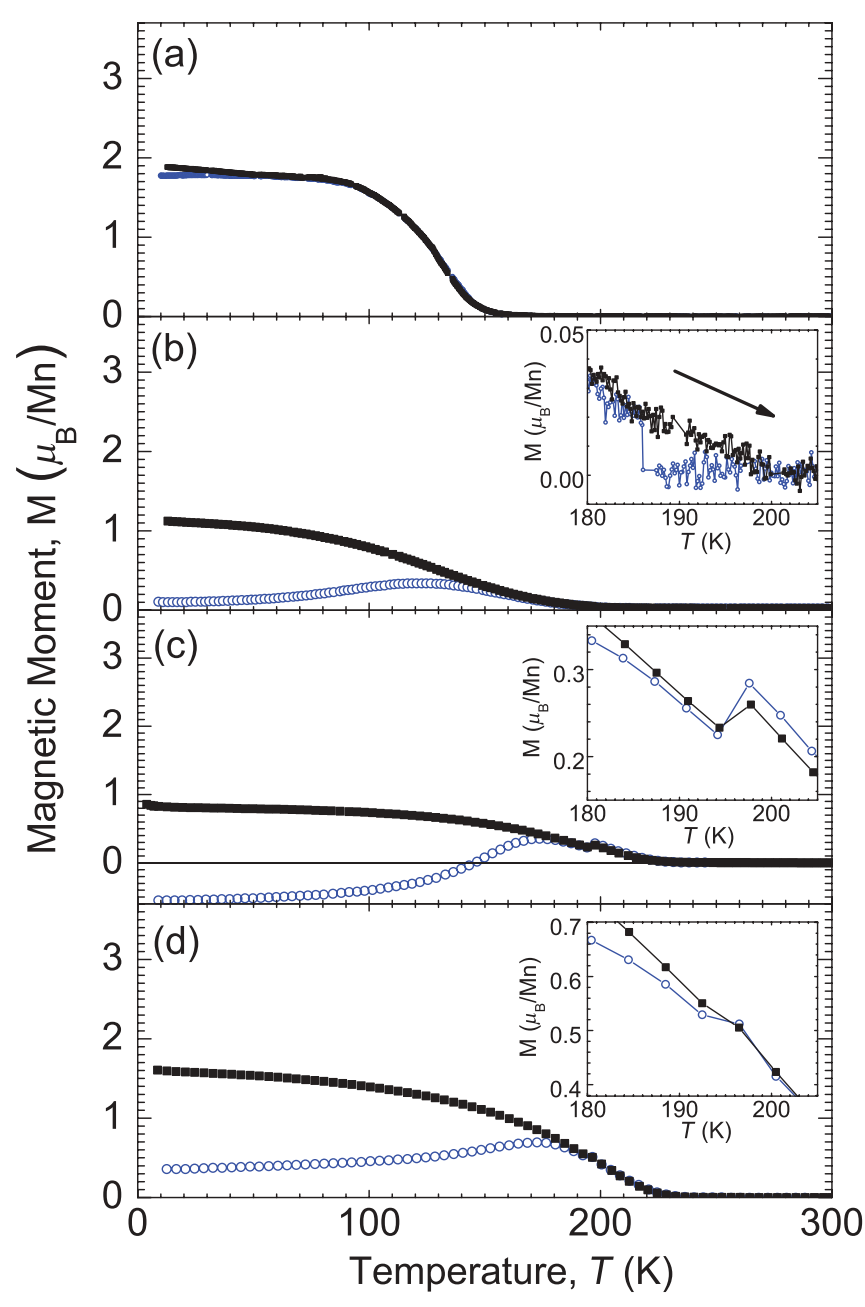

FIG. 4. (Color online) FC (black squares) and ZFC (blue circles) temperature-dependent magnetic moments for 120 - $\AA$-thick $\mathrm{La}_{0.7} \mathrm{Ca}_{0.3} \mathrm{MnO}_{3}$ film on (a) $\mathrm{SrTiO}_{3}$, (b) poled $\mathrm{BaTiO}_{3}$, (c) unpoled $\mathrm{BaTiO}_{3}$, and (d) 150- $\AA$-thick $\mathrm{La}_{0.7} \mathrm{Ca}_{0.3} \mathrm{MnO}_{3}$ on unpoled $\mathrm{BaTiO}_{3}$ measured in $100 \mathrm{Oe}$. Insets highlight the magnetic moment jumps at the $\mathrm{R}-\mathrm{O} \mathrm{BaTiO}_{3}$ transition.

the strong influence of the surface morphology (different in the two phases, as observed in the SPM topographical images) on the magnetic properties of the $\mathrm{La}_{0.7} \mathrm{Ca}_{0.3} \mathrm{MnO}_{3}$ film. The observed magnetic moment difference between the two phases at $190 \mathrm{~K}$ is compatible with differences stemming either from substrate-induced strain (via magnetoelastic and magnetostrictive coupling) or from electric polarization [via giant converse magnetoelectric coupling with coefficients of the order of magnitude determined for $\mathrm{La}_{0.7} \mathrm{Sr}_{0.3} \mathrm{MnO}_{3}$ on $\mathrm{BaTiO}_{3}$ (Ref. 10) and for $300-\AA \mathrm{La}_{0.7} \mathrm{Ca}_{0.3} \mathrm{MnO}_{3}$ on relaxor substrate $\mathrm{Pb}\left(\mathrm{Mg}_{1 / 3} \mathrm{Nb}_{2 / 3}\right)_{0.72} \mathrm{Ti}_{0.28} \mathrm{O}_{3}$ (Ref. 30)] or a combination of both.

\section{Resistivity}

The exotic magnetic behavior of $\mathrm{La}_{0.7} \mathrm{Ca}_{0.3} \mathrm{MnO}_{3} / \mathrm{BaTiO}_{3}$ shows up in its electronic transport properties. Figure 7 compares the temperature-dependent resistivity of $\mathrm{La}_{0.7} \mathrm{Ca}_{0.3}$ $\mathrm{MnO}_{3} / \mathrm{SrTiO}_{3}$ and various $\mathrm{La}_{0.7} \mathrm{Ca}_{0.3} \mathrm{MnO}_{3} / \mathrm{BaTiO}_{3}$ samples. There are large differences between $\mathrm{La}_{0.7} \mathrm{Ca}_{0.3} \mathrm{MnO}_{3} / \mathrm{SrTiO}_{3}$ 

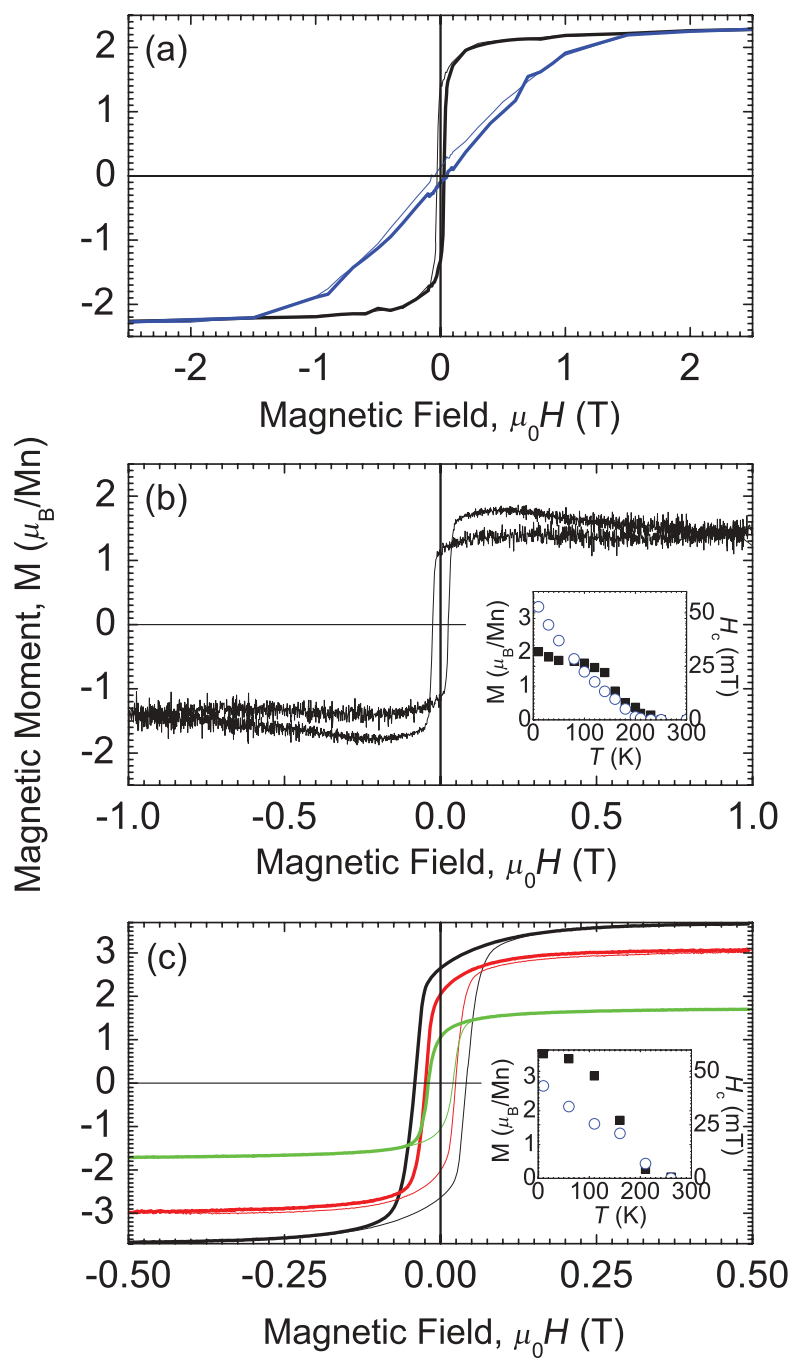

FIG. 5. (Color online) (a) Magnetization hysteresis cycles of 120- $\AA$-thick $\mathrm{La}_{0.7} \mathrm{Ca}_{0.3} \mathrm{MnO}_{3} / \mathrm{BaTiO}_{3}$ at $30 \mathrm{~K}$, (b) with magnetic field applied parallel (black lines) and normal (blue/medium gray lines) and at $120 \mathrm{~K}$ exhibiting Matteucci magnetic loops. (c) Magnetization hysteresis cycles at $160 \mathrm{~K}$ (green/gray), $120 \mathrm{~K}$ (red/dark gray), and at $10 \mathrm{~K}$ (black) of 240 - $\AA$-thick $\mathrm{La}_{0.7} \mathrm{Ca}_{0.3} \mathrm{MnO}_{3} / \mathrm{BaTiO}_{3}$. Insets to (b) and (c): Coercive fields (blue circles) and saturation moments (black squares).

and $\mathrm{La}_{0.7} \mathrm{Ca}_{0.3} \mathrm{MnO}_{3} / \mathrm{BaTiO}_{3}$. The $\mathrm{La}_{0.7} \mathrm{Ca}_{0.3} \mathrm{MnO}_{3} / \mathrm{SrTiO}_{3}$ follows the behavior expected for an optimally doped thin epitaxial manganite layer: there is a metal insulator transition $\left(T_{\mathrm{MI}}\right)$ near the Curie temperature, which shifts towards higher temperature when increasing the applied field. ${ }^{21}$ The resistivity and magnetoresistance are very low at low temperatures with negligible thermal hysteresis.

Thin $(120 \AA) \mathrm{La}_{0.7} \mathrm{Ca}_{0.3} \mathrm{MnO}_{3} / \mathrm{BaTiO}_{3}$ samples exhibit two hysteretic jumps, coinciding with the two first-order structural transitions of $\mathrm{BaTiO}_{3}$ at $T_{\mathrm{R}-\mathrm{O}}=188 \mathrm{~K}(196 \mathrm{~K})$ and $T_{\mathrm{O}-\mathrm{T}}=283 \mathrm{~K}(293 \mathrm{~K})$ upon cooling (warming). Remarkably, the resistivity variation at the R-O transition, $\Delta \rho_{\mathrm{R}-\mathrm{O}}$, exceeds two orders of magnitude and overlaps with the usual M-I transition near $T_{\mathrm{c}}$. This resistivity jump is sample dependent, although in most cases, it runs from higher resistance at the high-temperature

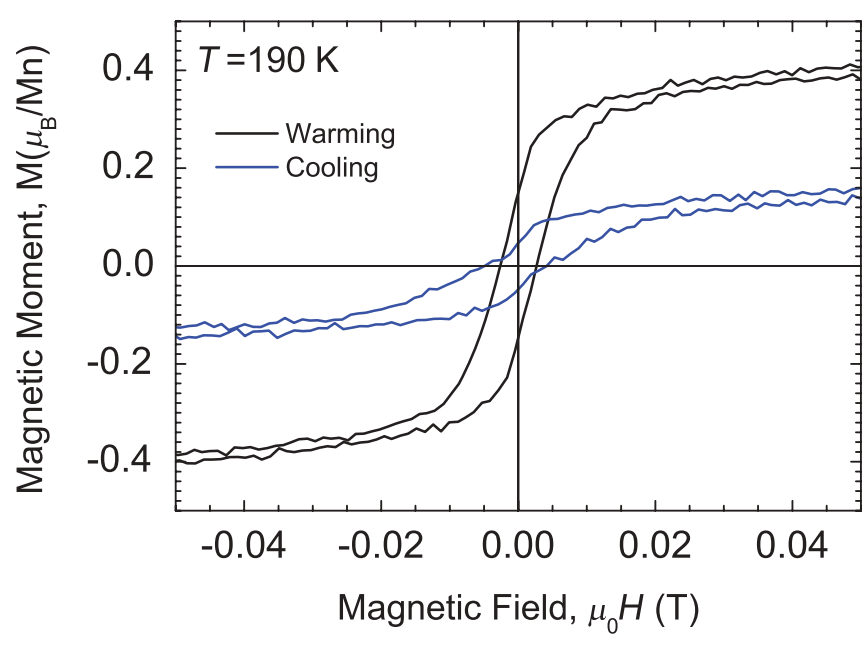

FIG. 6. (Color online) Magnetization hysteresis loops at $190 \mathrm{~K}$ after warming from $10 \mathrm{~K}$ (black lines) and cooling from $300 \mathrm{~K}$ (blue lines) at the hysteretic R-O transition of $\mathrm{BaTiO}_{3}$ for $120 \AA$ $\mathrm{La}_{0.7} \mathrm{Ca}_{0.3} \mathrm{MnO}_{3} / \mathrm{BaTiO}_{3}$.

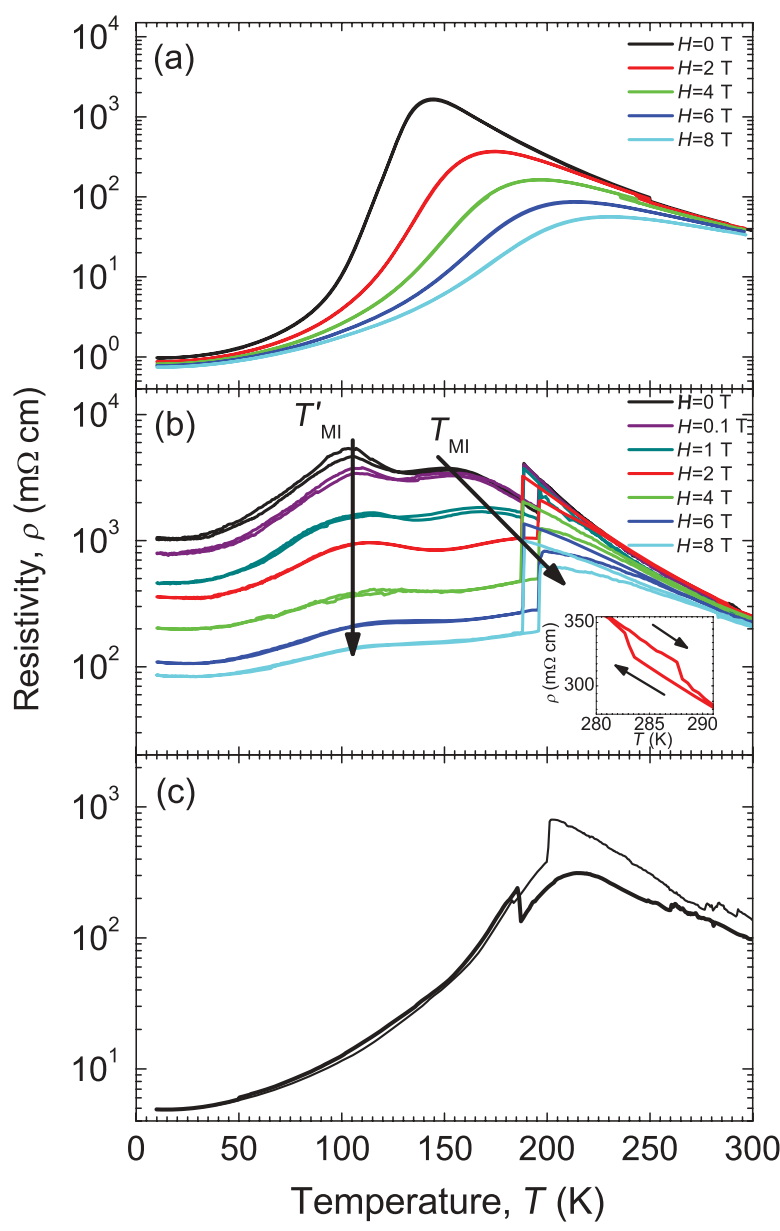

FIG. 7. (Color online) Temperature-dependent resistivity of (a) $\mathrm{La}_{0.7} \mathrm{Ca}_{0.3} \mathrm{MnO}_{3} / \mathrm{SrTiO}_{3}$, (b) $\mathrm{La}_{0.7} \mathrm{Ca}_{0.3} \mathrm{MnO}_{3} / \mathrm{BaTiO}_{3}$ in several in-plane magnetic fields, arrows are guides to the eye, (c) $\mathrm{La}_{0.7} \mathrm{Ca}_{0.3} \mathrm{MnO}_{3} / \mathrm{BaTiO}_{3}, 240 \AA$ showing one $\mathrm{MI}$ transition and strong hysteretic behavior. Inset shows the hysteretic jumps in resistivity at the $\mathrm{T}-\mathrm{O} \mathrm{BaTiO}_{3}$ transition. 
side to lower resistance at the low-temperature side. This is consistent with the typically observed upwards jump of the magnetization as the temperature is lowered. Nevertheless, the sign of $\Delta \rho_{\mathrm{R}-\mathrm{O}}$ may differ even between simultaneous measurements along the two perpendicular sample edges in the van der Pauw geometry; this is suggestive of the importance of the distribution of ferroelectric domains in $\mathrm{BaTiO}_{3}$ for the conductance pathways which may differ from one sample to another and be further affected by thermal history. Indeed, most thin $\mathrm{La}_{0.7} \mathrm{Ca}_{0.3} \mathrm{MnO}_{3} / \mathrm{BaTiO}_{3}(120 \AA)$ samples show two metal insulator transitions at around $T_{\mathrm{MI}}=160 \mathrm{~K}$ and $T_{\mathrm{MI}}^{\prime}=100 \mathrm{~K}$, respectively coinciding with the onset of ferromagnetism at $T_{\mathrm{C}}$ and slightly below the blocking of the magnetic system around $120 \mathrm{~K}$. Here, $T_{\mathrm{MI}}$ increases from $160 \mathrm{~K}$ in zero magnetic field to above $260 \mathrm{~K}$ for an applied field of $8 \mathrm{~T}$ [see Fig. 7(b)], a behavior similar to that observed for $\mathrm{La}_{0.7} \mathrm{Ca}_{0.3} \mathrm{MnO}_{3} / \mathrm{SrTiO}_{3}$ and as expected for the conventional MI transition of optimally doped manganites. ${ }^{21}$ This is not the case for $T^{\prime}{ }_{\text {MI }}$. It hardly shifts with field, demonstrating the appearance of a fraction of magnetic moments quite insensitive to the application of an external magnetic field and forming insulating regions. When measuring with field perpendicular to the sample plane, the observed phenomenology is qualitatively the same as with the field parallel to it.

There is a striking hysteretic thermal behavior of $\mathrm{La}_{0.7} \mathrm{Ca}_{0.3} \mathrm{MnO}_{3} / \mathrm{BaTiO}_{3}$. Figure 8 shows the temperature dependence of the difference of resistivity $(\Delta \rho)$ between warming and cooling runs (note the logarithmic scale). Irreversibilities $(\Delta \rho>0)$ are apparent around both metalinsulator transitions, although they are far more pronounced for the $T_{\mathrm{MI}}^{\prime}$ freezing transition in zero field and, curiously enough, are also strongly enhanced in the paramagnetic region. The latter persists up to the highest fields studied. Also, irreversibilities around $T_{\mathrm{MI}}^{\prime}$ are very sensitive to the application of an external magnetic field. This observation rules out secondary and nonstoichiometric fractions as responsible for the appearance of a second transition at $T_{\mathrm{MI}}^{\prime}$. The R-O BaTiO structural transition trivially yields very large $\Delta \rho$ between 188 and $196 \mathrm{~K}$, due to its hysteretic nature.

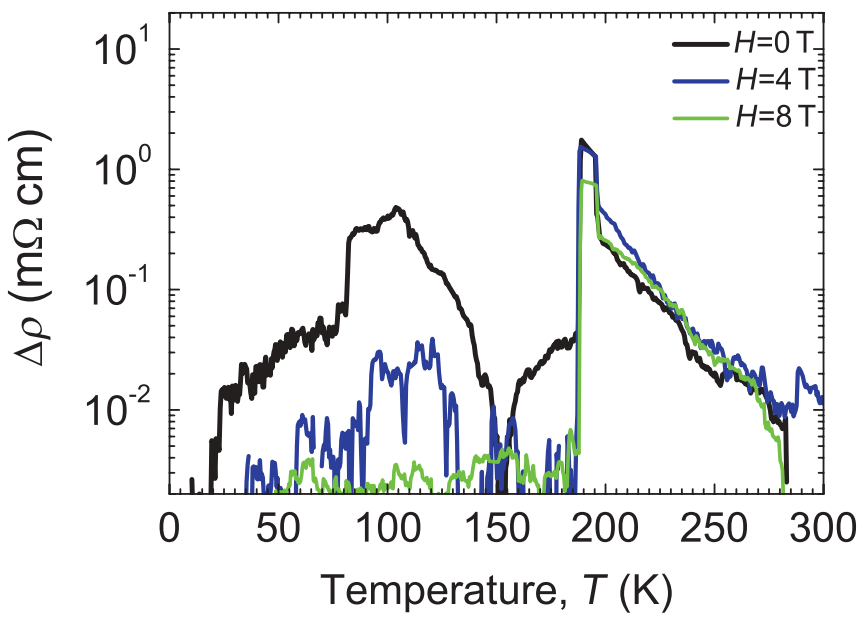

FIG. 8. (Color online) Temperature dependence of thermal resistivity hysteresis $(\Delta \rho)$ in selected magnetic fields: $0 \mathrm{~T}$ (black), $4 \mathrm{~T}$ (blue), and $8 \mathrm{~T}$ (green).

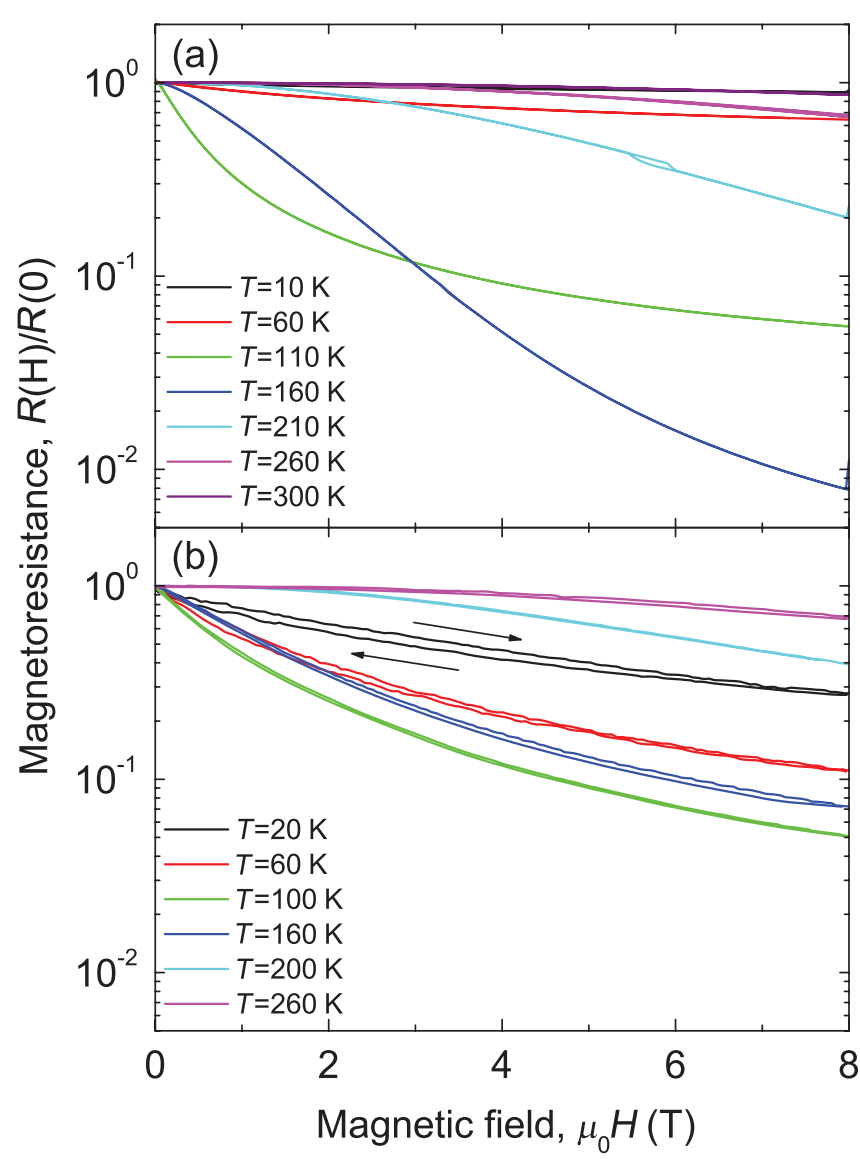

FIG. 9. (Color online) Magnetoresistance of (a) $\mathrm{La}_{0.7} \mathrm{Ca}_{0.3}$ $\mathrm{MnO}_{3} / \mathrm{SrTiO}_{3}$ and (b) $\mathrm{La}_{0.7} \mathrm{Ca}_{0.3} \mathrm{MnO}_{3} / \mathrm{BaTiO}_{3}$ at selected temperatures (thickness: $120 \AA$ in the two cases).

\section{Magnetoresistance}

The isothermal magnetoresistance (MR) also reveals important differences between $\mathrm{La}_{0.7} \mathrm{Ca}_{0.3} \mathrm{MnO}_{3} / \mathrm{SrTiO}_{3}$ and $\mathrm{La}_{0.7} \mathrm{Ca}_{0.3} \mathrm{MnO}_{3} / \mathrm{BaTiO}_{3}$. Figure 9 shows the fielddependent MR at several temperatures for $120-\AA$ thick $\mathrm{La}_{0.7} \mathrm{Ca}_{0.3} \mathrm{MnO}_{3} / \mathrm{SrTiO}_{3}$ and $\mathrm{La}_{0.7} \mathrm{Ca}_{0.3} \mathrm{MnO}_{3} / \mathrm{BaTiO}_{3}$. Colossal MR ratios are observed at temperatures near $T_{\mathrm{C}}$ as expected in optimally doped manganites. For thin (120 ̊) $\mathrm{La}_{0.7} \mathrm{Ca}_{0.3} \mathrm{MnO}_{3} / \mathrm{BaTiO}_{3}$, large and hysteretic MR is observed at low temperatures that is absent in either $\mathrm{La}_{0.7} \mathrm{Ca}_{0.3} \mathrm{MnO}_{3} / \mathrm{SrTiO}_{3}$ or thicker $\mathrm{La}_{0.7} \mathrm{Ca}_{0.3} \mathrm{MnO}_{3} / \mathrm{BaTiO}_{3}$. Again, hysteretic behavior, this time with applied field, is observed for the thin $\mathrm{La}_{0.7} \mathrm{Ca}_{0.3} \mathrm{MnO}_{3} / \mathrm{BaTiO}_{3}$ over a broad temperature range. For temperatures above $T_{\mathrm{MI}}$, hysteresis is also present in $\mathrm{La}_{0.7} \mathrm{Ca}_{0.3} \mathrm{MnO}_{3} / \mathrm{SrTiO}_{3}$, as expected from the percolative nature of the transition. The MR of $\mathrm{La}_{0.7} \mathrm{Ca}_{0.3} \mathrm{MnO}_{3} / \mathrm{BaTiO}_{3}$ remains large at low temperature, indicating lack of complete magnetic ordering. This is in agreement with the granular magnetic behavior exhibited below the freezing temperature.

\section{E. Poling}

To explore the role of ferroelectric $\mathrm{BaTiO}_{3}$ domains in the magnetic and electronic properties of $\mathrm{La}_{0.7} \mathrm{Ca}_{0.3}$ $\mathrm{MnO}_{3} / \mathrm{BaTiO}_{3}$, we study the effect on the film resistivity of 


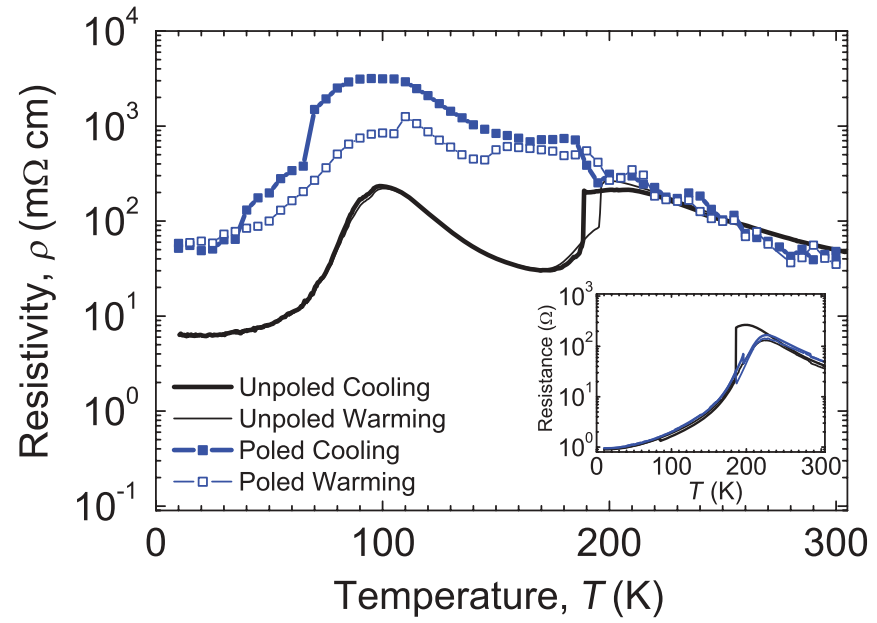

FIG. 10. (Color online) Temperature-dependent resistivity of 120- $\AA$-thick $\mathrm{La}_{0.7} \mathrm{Ca}_{0.3} \mathrm{MnO}_{3} / \mathrm{BaTiO}_{3}$ before (black lines) and after (blue lines) poling the $\mathrm{BaTiO}_{3}$ substrate. The inset shows data for a thicker sample (150 ̊).

electrically poling the substrate at room temperature. Figure 10 shows the resistivity of a thin $(120 \AA)$ film before and after $\mathrm{BaTiO}_{3}$ poling. Upon cooling after poling, the peak at $T_{\mathrm{MI}}^{\prime}$ remains, while the transition at $T_{\mathrm{MI}}$ is practically obscured by the change induced by the O-R structural transition. The low-temperature resistivity increases an order of magnitude after poling and thermal hysteresis is strongly enhanced. Note also the sign change of $\Delta \rho$ upon approaching the O-R transition from below. In spite of this hysteretic behavior, the high-temperature resistance remains unchanged, assuring the reproducibility of the current paths (i.e. lack of fractures). In thicker $\mathrm{La}_{0.7} \mathrm{Ca}_{0.3} \mathrm{MnO}_{3} / \mathrm{BaTiO}_{3}$, the effect of the $\mathrm{BaTiO}_{3}$ morphology on transport properties can also be appreciated: the resistivity around the $\mathrm{O}-\mathrm{R}$ transition is dramatically altered upon poling (inset to Fig. 10), even though $T^{\prime}$ MI was not seen either before or after poling.

\section{F. Electroresistance}

A complementary phenomenon to magnetoresistance, ${ }^{31}$ electroresistance, refers in its broadest to any nonlinear current-voltage characteristics. Figure 11 shows the voltagedependent normalized resistivity $R / R_{0}$ curves (where $R_{0}$ is low bias resistance) at selected temperatures for $120-\AA$-thin films of $\mathrm{La}_{0.7} \mathrm{Ca}_{0.3} \mathrm{MnO}_{3} / \mathrm{SrTiO}_{3}$ and $\mathrm{La}_{0.7} \mathrm{Ca}_{0.3} \mathrm{MnO}_{3} /$ $\mathrm{BaTiO}_{3}$. Contrary to the $\mathrm{La}_{0.7} \mathrm{Ca}_{0.3} \mathrm{MnO}_{3} / \mathrm{SrTiO}_{3}$ case, where it is negligible, $\mathrm{ER}$ in $\mathrm{La}_{0.7} \mathrm{Ca}_{0.3} \mathrm{MnO}_{3} / \mathrm{BaTiO}_{3}$ is significant and nontrivial. For the former, the resistance is either ohmic (linear, e.g. at $200 \mathrm{~K})$ or decreases slightly $\left(\Delta R / R_{0}<1 \%\right.$, e.g. at $100 \mathrm{~K}$ and the low-voltage part at $10 \mathrm{~K}$ ). The increase of resistance with voltage in $\mathrm{La}_{0.7} \mathrm{Ca}_{0.3} \mathrm{MnO}_{3} / \mathrm{SrTiO}_{3}$ (e.g. at 10 or $140 \mathrm{~K}$ ) is a mere consequence of Joule heating in the metallic regime. This extreme was also checked with pulsed measurements at certain temperatures. Electroresistance in $\mathrm{La}_{0.7} \mathrm{Ca}_{0.3} \mathrm{MnO}_{3} / \mathrm{BaTiO}_{3}$ reaches $20 \%$ at $T=150 \mathrm{~K}$ and $V=1 \mathrm{~V}$. Once again, the upturn of $R / R_{0}$ for $V>1 \mathrm{~V}$ is a consequence of Joule heating and is not considered in our analysis. In order to quantify these data, we define the ER threshold voltage $V_{\text {th }}$ as the voltage where R departs

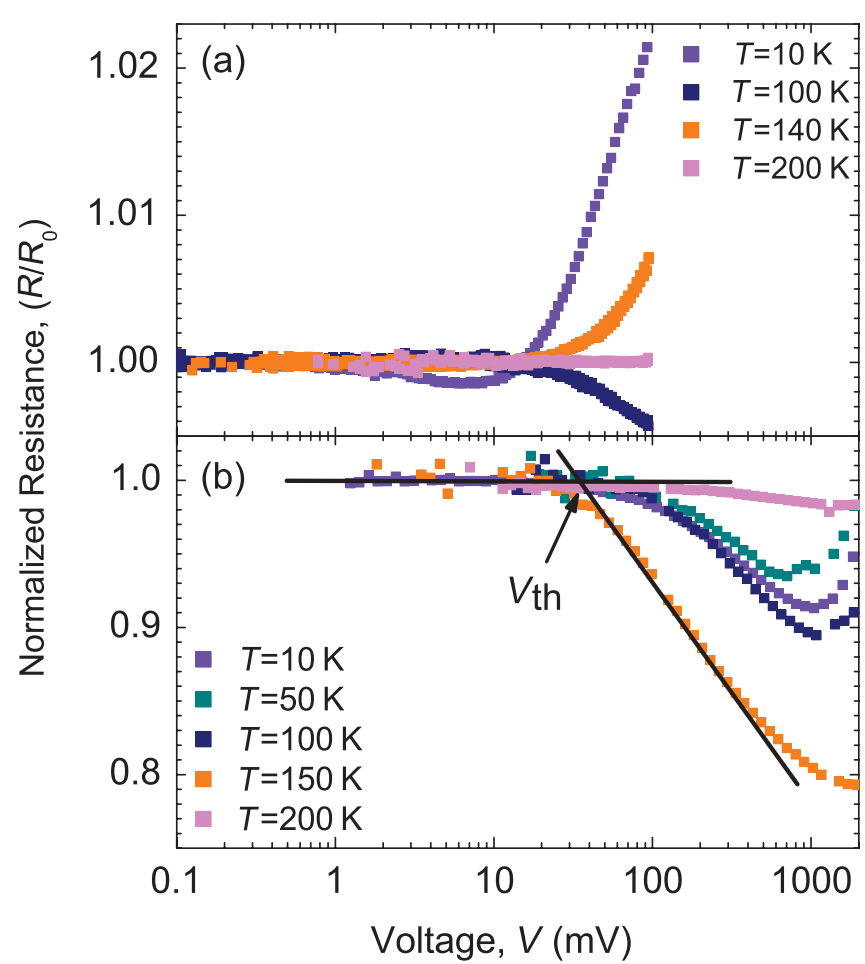

FIG. 11. (Color online) Resistance vs applied voltage for (a) $\mathrm{La}_{0.7} \mathrm{Ca}_{0.3} \mathrm{MnO}_{3} / \mathrm{SrTiO}_{3}$ and (b) $\mathrm{La}_{0.7} \mathrm{Ca}_{0.3} \mathrm{MnO}_{3} / \mathrm{BaTiO}_{3}$ normalized to the low bias value $R_{0}$ at selected temperatures.

from ohmic behavior [as illustrated in Fig. 11(b)], and ER as $\Delta R / R_{0}=\left(R(V)-R_{0}\right) / R_{0}$ for $V=2 V_{\text {th }}$. We summarize these data in Figs. 12(a) and 12(b) showing the temperature dependence of threshold voltage $V_{\text {th }}$ and ER, respectively. The threshold voltage has a broad dip centered around $T \approx 130-160 \mathrm{~K}$, coinciding with the strongest ER. These salient changes of ER and threshold voltage occur in the temperature range where anomalies in the magnetic hysteresis cycles are observed and also near $T_{\mathrm{MI}}^{\prime}$. Note that the rather small magnitude of ER (up to $4 \%$ ) is only due to our operational definition of ER, taken at $V=2 V_{\text {th }}$. To summarize our electroresistance experiments, $\mathrm{La}_{0.7} \mathrm{Ca}_{0.3} \mathrm{MnO}_{3} / \mathrm{BaTiO}_{3}$ shows very steep and large resistance drop above threshold up to $T_{\mathrm{MI}}$, as opposed to $\mathrm{La}_{0.7} \mathrm{Ca}_{0.3} \mathrm{MnO}_{3} / \mathrm{SrTiO}_{3}$, which barely displays a temperature-dependent ER.

\section{DISCUSSION}

From the structural and topographic data, the following picture of $\mathrm{La}_{0.7} \mathrm{Ca}_{0.3} \mathrm{MnO}_{3} / \mathrm{BaTiO}_{3}$ emerges. The films are epitaxial with structural coherence volumes on the order of (70-90) $\times 200 \times 200 \AA^{3}$ and characterized by a biaxial strain largely compressive out of plane and tensile in plane. The strained $\mathrm{La}_{0.7} \mathrm{Ca}_{0.3} \mathrm{MnO}_{3}$ film adjusts to the lattice changes experienced by $\mathrm{BaTiO}_{3}$ upon cooling, heating, or poling, exhibiting hysteretic behavior at the $\mathrm{BaTiO}_{3}$ phase transitions. Since through these phase transitions the two tetragonal lattice constants of the substrate eventually merge into a single value corresponding to the rhombohedral lattice constant (see Fig. 1 and Table I), we assume the $\mathrm{La}_{0.7} \mathrm{Ca}_{0.3} \mathrm{MnO}_{3}$ layer to elastically smear out any strain differences between 


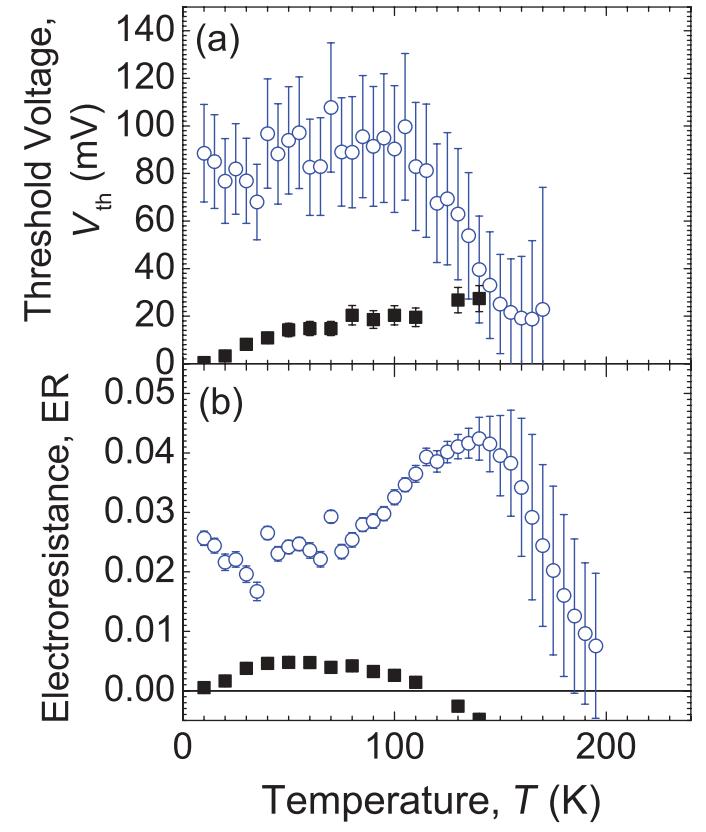

FIG. 12. (Color online) (a) Threshold voltage and (b) electroresistance for $\mathrm{La}_{0.7} \mathrm{Ca}_{0.3} \mathrm{MnO}_{3} / \mathrm{SrTiO}_{3}$ (black solid squares) and $\mathrm{La}_{0.7} \mathrm{Ca}_{0.3} \mathrm{MnO}_{3} / \mathrm{BaTiO}_{3}$ (blue open circles) as a function of temperature.

$\mathrm{La}_{0.7} \mathrm{Ca}_{0.3} \mathrm{MnO}_{3}$ cells on ferroelectric domains in the $\mathrm{T}$ and $\mathrm{O}$ phases. This assumption can only be validated in part by our low-temperature structural study: ${ }^{18}$ the observed $\mathrm{La}_{0.7} \mathrm{Ca}_{0.3} \mathrm{MnO}_{3}$ peak exhibits a single maximum, but it is substantially broad. On the basis of our SPM observations, we expect multiple $\mathrm{FE}$ domains in our $\mathrm{BaTiO}_{3}$ substrates. These domains will be arranged in patterns determined largely by the ferroelectric-elastic equilibrium reached in the bulk at each temperature with only minimal contributions from the depolarizing field introduced by the changing conduction properties of the $\mathrm{La}_{0.7} \mathrm{Ca}_{0.3} \mathrm{MnO}_{3}$ layer. ${ }^{32}$ Thus, it is necessary to discuss the properties exhibited by the $\mathrm{La}_{0.7} \mathrm{Ca}_{0.3} \mathrm{MnO}_{3}$ thin films in terms of the structural changes experienced by the $\mathrm{BaTiO}_{3}$ substrate, since the layer remains epitaxial. The limited coherence (70-90 $\AA$ ) in the out-of-plane direction is consistent with a corrugated $\mathrm{La}_{0.7} \mathrm{Ca}_{0.3} \mathrm{MnO}_{3} / \mathrm{BaTiO}_{3}$ interface. ${ }^{18}$ In the $\mathrm{T}$ phase of $\mathrm{BaTiO}_{3}$, a characteristic corrugation angle of $0.6^{\circ}$ is introduced by $90^{\circ}$ domain walls. Upon cooling $\mathrm{BaTiO}_{3}$ substrates through the $\mathrm{O}$ phase, the topography and diffraction pattern introduced by the new FE domain structure is not significantly different from that of the $\mathrm{T}$ phase. In contrast, the transition to the $\mathrm{R}$ phase introduces a secondary corrugation (there is good agreement between the experimental values for the corrugation angle determined from SPM and x-ray diffraction), which only becomes stable at $100 \mathrm{~K}$, within the time required for SPM imaging. Recent results with a phenomenological Ginzburg-Landau-Devonshire model ${ }^{33}$ predict $71^{\circ}$ and $109^{\circ}$ domain walls in the $\mathrm{R}$ phase to be as thin and stable as the $180^{\circ}$ domain walls in the T phase. Note that with $109^{\circ}$ domain walls, the expected corrugation by reflection twinning in $(001) \mathrm{R}$ planes is $2^{*}(90-\alpha)=0.3^{\circ}$, where $\alpha$ is the rhombohedral angle. The presence of both corrugations makes the morphology of the $\mathrm{BaTiO}_{3}$ surface in the $\mathrm{R}$ phase more fine grained, introducing a new characteristic length scale (in the micron range). Consequently, we have experimental and theoretical support for added phenomenology for $\mathrm{La}_{0.7} \mathrm{Ca}_{0.3} \mathrm{MnO}_{3}$ on rhombohedral $\mathrm{BaTiO}_{3}$ with respect to higher temperatures.

This complex structure has a strong influence on the magnetic properties of thin $\mathrm{La}_{0.7} \mathrm{Ca}_{0.3} \mathrm{MnO}_{3} / \mathrm{BaTiO}_{3}(120 \AA)$ :

(1) Firstly, the Curie transition is broadened, the coercive field is one order of magnitude larger than in the reference $\mathrm{La}_{0.7} \mathrm{Ca}_{0.3} \mathrm{MnO}_{3} / \mathrm{SrTiO}_{3}$, and a clear anomaly appears in the temperature-dependent magnetization below the $\mathrm{O}-\mathrm{R}$ transition, indicating magnetic moment blocking or freezing and granular magnetic behavior.

(2) Secondly, almost half of the expected $3.7 \mu_{\mathrm{B}} / \mathrm{Mn}$ magnetic moments are missing and do not orient even at low temperature and high field $(5 \mathrm{~T})$ implying that an important fraction of magnetic moments are not participating in long-range FM order. These show up actively in the anomalous Matteucci-like hysteresis loops, as well as in the enhancement of the out-of-plane saturation moment in high field. On magnetoelastic grounds, Matteucci-like cycles have been shown to be consistent with the existence of an out-of-plane spin population (amounting to approximately $1 / 3$ of the available spins) that is moderately sensitive to magnetic field. ${ }^{18}$ Thicker $\mathrm{La}_{0.7} \mathrm{Ca}_{0.3} \mathrm{MnO}_{3} / \mathrm{BaTiO}_{3}$ films hardly show missing magnetic moment, but their coercive fields are much larger than those of the reference $\mathrm{La}_{0.7} \mathrm{Ca}_{0.3} \mathrm{MnO}_{3} / \mathrm{SrTiO}_{3}$. The observation of depressed magnetic moment could also be compatible with AFM behavior below its spin-flip field coexisting with in-plane FM regions.

(3) Thirdly, negative magnetization (i.e. opposing the applied field) is observed in low fields at low temperature in certain samples. This behavior is characteristic of frozen AFM correlations in a frustrated system. ${ }^{34-36}$

Magnetotransport properties are extremely sensitive to changes in double-exchange interactions, which are in turn strongly affected by the variations in the angles between $\mathrm{MnO}_{6}$ octahedra induced by strain or by changes in the crystal field. Unlike in $\mathrm{La}_{0.7} \mathrm{Ca}_{0.3} \mathrm{MnO}_{3} / \mathrm{SrTiO}_{3}$ and bulk $\mathrm{La}_{0.7} \mathrm{Ca}_{0.3} \mathrm{MnO}_{3}$, $\mathrm{La}_{0.7} \mathrm{Ca}_{0.3} \mathrm{MnO}_{3} / \mathrm{BaTiO}_{3}$ thin films (120 ̊) show two welldefined MI transitions. Here, $T_{\mathrm{MI}}$ is described as the usual metal-insulator transitions in FM perovskite manganites: ${ }^{19-21}$ insulating clusters intermixed into the long-range conducting FM order grow with increasing temperature, and electronic transport becomes dominated by electric percolation through FM regions. Above $T_{\mathrm{c}}$, the usual paramagnetic insulating ordering appears. A magnetic field strengthens the FM clusters and shifts the transition to higher temperature. However, the second transition, $T_{\mathrm{MI}}^{\prime}$, does not fit this picture as the magnetic field does not shift this transition temperature. This suggests that the clusters responsible for this $T_{\mathrm{MI}}^{\prime}$ are not affected by the magnetic field, unlike the paramagnetic regions in the usual MI transition. The considerable magnetoresistance is then due to the interface between small FM and nonFM regions. Irreversibility between cooling and warming is usually considered a signature of the percolative nature of the transition. Around $T_{\mathrm{MI}}^{\prime}$ the phase-separation balance changes, favoring the insulating non-FM clusters. Structural changes of the substrate, evolution of the surface morphology, drive the competition between phases, and this translates to a highly hysteretic MI transition. 
Although, most of our experimental data can be interpreted solely on the basis of the purely FM order with spatially inhomogenous anisotropy (coexisting regions of in-plane and outof-plane FM interaction), other ingredients may play a role. Hints come from the negative magnetization measured in the ZFC of some samples and the hard and insulating behavior of the spins responsible for $T_{\mathrm{MI}}^{\prime}$ transition. We propose that AFM correlations could be enhanced in $\mathrm{La}_{0.7} \mathrm{Ca}_{0.3} \mathrm{MnO}_{3} / \mathrm{BaTiO}_{3}$ close to the $\mathrm{BaTiO}_{3}$ interface beyond the level expected in optimally doped bulk and thin film manganites (and that should be also present to a much lesser extent in $\mathrm{La}_{0.7} \mathrm{Ca}_{0.3} \mathrm{MnO}_{3} / \mathrm{SrTiO}_{3}$ and thicker $\mathrm{La}_{0.7} \mathrm{Ca}_{0.3} \mathrm{MnO}_{3} / \mathrm{BaTiO}_{3}$ samples). In this picture, $\mathrm{La}_{0.7} \mathrm{Ca}_{0.3} \mathrm{MnO}_{3} / \mathrm{BaTiO}_{3}$ thin films consist of FM regions interspersed with AFM ones, with strong magnetic frustration at their boundaries.

What would be the origin of this enhancement of AFM interactions in an optimally $(x=0.3)$ doped manganite thin film? We first consider tetragonal distortion induced by strain which affects orbital ordering. Indeed, for $\mathrm{La}_{1-x} \mathrm{Sr}_{x} \mathrm{MnO}_{3}$ (Ref. 37), the phase diagram calculated from first principles show the stability region of the FM order to be largely reduced: for $x=0.3$ doping in $\mathrm{La}_{0.7} \mathrm{Sr}_{0.3} \mathrm{MnO}_{3}, c / a<0.96$ corresponds to AFM order. For our $\mathrm{La}_{0.7} \mathrm{Ca}_{0.3} \mathrm{MnO}_{3} / \mathrm{BaTiO}_{3}$ samples, the $c / a$ ratio for $\mathrm{La}_{0.7} \mathrm{Ca}_{0.3} \mathrm{MnO}_{3}$ can be estimated in the $\mathrm{R}$ phase of $\mathrm{BaTiO}_{3}$ from synchrotron x-ray diffraction, giving $c / a=0.98$ at $132 \mathrm{~K}$ (Ref. 18), implying FM order. However, in line with the magnetoelastic model proposed in Ref. 18, we may assume that the cells of the $\mathrm{La}_{0.7} \mathrm{Ca}_{0.3} \mathrm{MnO}_{3}$ layer lying close to $\mathrm{BaTiO}_{3}$ are severely strained with in-plane lattice parameters of $\mathrm{BaTiO}_{3}$. Under this hypothesis, the tetragonality ratio would be $c / a=0.94$, making the presence of AFM order plausible close to the interface.

Secondly, recent $a b$ initio and two-orbital model calculations explore the effect of the electric polarization of the FE on the magnetic state of manganite in connection with manganite/FE/manganite heterostructures. ${ }^{7-9}$ They conclude that interfacial spins, under various FE polarization scenarios, switch to non-FM arrangements, most of them concerning AFM coupling. In films thicker than a few atomic layers, AFM arrangements would therefore coexist with FM arrangements, giving rise to phase separation, similar to that observed in bulk $\mathrm{La}_{0.7} \mathrm{Ca}_{0.3} \mathrm{MnO}_{3}$ (Ref. 20). These effects predominate near the FM/FE interface over only a few unit cells, so the associated phenomenology blurs out in thicker films, akin to our observations.

With either the strain or electric-field-induced AFM mechanism, transport properties of the $\mathrm{La}_{0.7} \mathrm{Ca}_{0.3} \mathrm{MnO}_{3}$ layer will be very sensitive to the electric poling of the $\mathrm{BaTiO}_{3}$ substrate. In these conditions, magnetoelectric effects are expected, changing the equilibrium between the manganite microphases from that corresponding to a random polarization distribution. We observe precisely this (Fig. 10): upon poling, the resistance near $T_{\mathrm{MI}}^{\prime}$ increases, whereas the usual MI transition is depleted, showing that a larger fraction of the $\mathrm{La}_{0.7} \mathrm{Ca}_{0.3} \mathrm{MnO}_{3}$ could be in an AFM state. In the $\mathrm{R}$ phase, the polarization lies along the unit cell diagonals. A poling process perpendicular to the sample surface at room temperature enhances the formation of larger domains oriented parallel to the applied electric field. When cooling to the $\mathrm{R}$ phase, these FE domains remain with a large net component of polarization in the poling direction.
These domains can act as nucleation centers for the AFM patches. As the new FM and AFM magnetic domains develop simultaneously with decreasing temperature due to the new pattern of FE domains, no exchange bias in the hysteresis cycles is expected (indeed none is observed). $\mathrm{BaTiO}_{3} \mathrm{O}-\mathrm{R}$ transition would enhance phase separation. It is difficult to ascertain on quantitative grounds whether this behavior would be the same if an out-of-plane fraction of spins were enhanced upon poling. Note that despite the very high magnetic fields applied, it has been impossible to achieve alignment of the out-of-plane moments. This behavior would imply unusual and extremely high out-of-plane anisotropy values.

Whatever is the etiology of the unruly moment fraction, our model naturally leads to a granular metallic system, confirmed by the high resistivity and large magnetoresistance at low temperatures. Also, electroresistance is sensitive to conduction pathways and the associated distribution of potential barriers and thus is a good measure of electric inhomogeneity. Electroresistance is two orders of magnitude larger in $\mathrm{La}_{0.7} \mathrm{Ca}_{0.3} \mathrm{MnO}_{3} / \mathrm{BaTiO}_{3}$ at low temperature than in $\mathrm{La}_{0.7} \mathrm{Ca}_{0.3} \mathrm{MnO}_{3} / \mathrm{SrTiO}_{3}$, doubling further to a maximum around $140 \mathrm{~K}$ with a concomitant minimum of the threshold voltage (see Fig. 12). This again could point to a dramatic increase in the activation energies triggered by an enhancement of the AFM order well below both the $\mathrm{O}-\mathrm{R} \mathrm{BaTiO}_{3}$ transition and $T_{\mathrm{MI}}$.

The anomalous phenomenology found in the 60-150 K temperature range seems to be linked to the secondary corrugation introduced by ferroelectric domain walls and developing in the $\mathrm{BaTiO}_{3}$ substrate below $180 \mathrm{~K}$. These changes in morphology are a signature of changes in the characteristic lengths for strain and electric polarization fields and, given the strong interplay between structural, electronic, and spin degrees of freedom and electrostatic boundary conditions in $\mathrm{La}_{0.7} \mathrm{Ca}_{0.3} \mathrm{MnO}_{3}$, necessarily affect the magnetism of $\mathrm{La}_{0.7} \mathrm{Ca}_{0.3} \mathrm{MnO}_{3}$ near the interface. From our results, it is not possible to establish unambiguously the relative importance of strain, geometric, and electrostatic factors, and further experimental work is needed in this direction. However, it should be noted that: (i) within the $\mathrm{R}$ phase of $\mathrm{BaTiO}_{3}$, thermal lattice constant variations do not exceed $0.05 \%$ (Ref. 25); (ii) while primary corrugation has a characteristic length in the $15-\mu \mathrm{m}$ range, secondary corrugation reduces this magnitude by a factor of 2 ; and (iii) the magnetic and transport anomalies are not present in thicker $\mathrm{La}_{0.7} \mathrm{Ca}_{0.3} \mathrm{MnO}_{3} / \mathrm{BaTiO}_{3}$ samples. From (i), we can conclude that homogeneous in-plane strain effects cannot play a major role in causing the observed phenomenology; from (ii), we can expect a twofold increase in the rate of alternation of the sign of spontaneous electrostatic polarization of the $\mathrm{La}_{0.7} \mathrm{Ca}_{0.3} \mathrm{MnO}_{3} / \mathrm{BaTiO}_{3}$ interface by the substrate with its associated changes in $\mathrm{La}_{0.7} \mathrm{Ca}_{0.3} \mathrm{MnO}_{3}$ electronic and spin degrees of freedom; from (iii), a vertical gradient is a plausible option for the spatial distribution of the anomalies. We propose that, between 180 and $100 \mathrm{~K}$ and triggered by the O-R $\mathrm{BaTiO}_{3}$ phase transition, $\mathrm{La}_{0.7} \mathrm{Ca}_{0.3} \mathrm{MnO}_{3} / \mathrm{BaTiO}_{3}$ experiences a renormalization of the existing delicate equilibrium between intrinsic phases that was developing below $T_{\mathrm{MI}}$. These effects are overcome when ferromagnetism starts to be the dominant phase and smoothly pervades the system as the 
temperature is lowered below $60 \mathrm{~K}$. It is in this temperature range where $\mathrm{La}_{0.7} \mathrm{Ca}_{0.3} \mathrm{MnO}_{3} / \mathrm{BaTiO}_{3}$ is most sensitive to external magnetic fields (colossal magnetoresistence) or strain (shift in $T_{\mathrm{MI}}$ ), due to the almost degenerate structural, electronic, and spin degrees of freedom. Therefore, prior to reaching a robust FM state, below $60 \mathrm{~K}$ in our case, the system could be particularly prone to developing AFM phases, induced by external perturbations such as those induced by the evolving secondary corrugation. This is in line with previously reported experiments in $\mathrm{La}_{0.7} \mathrm{Ca}_{0.3} \mathrm{MnO}_{3}$ 150- $\AA$-thin films deposited on $\mathrm{LaAlO}_{3}$ where the existence of a charge order insulating phase at low temperatures has been demonstrated ${ }^{38}$ and correlated to the existence of large inhomogeneous strains induced during the thin layer growth process. In 50 $\mathrm{La}_{0.7} \mathrm{Ca}_{0.3} \mathrm{MnO}_{3}$ on $\mathrm{SrTiO}_{3}$ (Ref. 39), under uniform strain conditions, magnetic and transport measurements have been interpreted on the basis of the existence of an AF insulating phase which occupies nearly $70 \%$ of the film.

\section{v. CONCLUSIONS}

We have shown magnetic and transport property anomalies to be present around $60-150 \mathrm{~K}$ in $\mathrm{La}_{0.7} \mathrm{Ca}_{0.3} \mathrm{MnO}_{3} / \mathrm{BaTiO}_{3}$ thin films. An extra resistance peak appears around $120 \mathrm{~K}$ that is quite insensitive to magnetic field and is accompanied by a strong increase of the electroresistance. Thin $\mathrm{La}_{0.7} \mathrm{Ca}_{0.3} \mathrm{MnO}_{3} / \mathrm{BaTiO}_{3}$ films behave as a magnetic and metallic granular system, albeit they are structurally epitaxial. The anomalies disappear with increasing $\mathrm{La}_{0.7} \mathrm{Ca}_{0.3} \mathrm{MnO}_{3}$ thickness, suggesting a vertically segregated structure. We have argued that the evolving surface morphology of the ferroelectric $\mathrm{BaTiO}_{3}$ substrate and its associated strain and electric field changes could enhance phase separation between AFM and FM local order in the $\mathrm{La}_{0.7} \mathrm{Ca}_{0.3} \mathrm{MnO}_{3}$ layer, in line with current theoretical studies. However, an alternative explanation based solely on coexisting in-plane and out-of-plane FM populations cannot be ruled out. The magnetic/metallic granularity and all anomalies can be explained by the intimate mixing of AFM and FM regions or, alternatively, in-plane and out-of-plane FM patches. A neat magnetoelectric coupling is apparent upon poling, and probably both strain and electron doping effects are at the root of our observations.

\section{ACKNOWLEDGMENTS}

CM and NMN acknowledge Spanish MINECO for Juan de la Cierva and Ramón y Cajal fellowships. This work was supported by the Spanish MINECO through Grant Nos. MAT2011-27470-C02-01 and MAT2011-27470-C02-02.
${ }^{1}$ M. Bibes, J. E. Villegas, and A. Barthélémy, Adv. Phys. 60, 5 (2011).

${ }^{2}$ C. A. F. Vaz and C. H. Ahn, in Ferroelectrics-Physical Effects, edited by Mickaël Lallart (InTech, 2011), p. 329.

${ }^{3}$ D. Khomskii, Physics 2, 20 (2009).

${ }^{4}$ S. Valencia, A. Crassous, L. Bocher, V. Garcia, X. Moya, R. O. Cherifi, C. Deranlot, K. Bouzehouane, S. Fusil, A. Zobelli, A. Gloter, N. D. Mathur, A. Gaupp, R. Abrudan, F. Radu, A. Barthélémy, and M. Bibes, Nat. Mater. 10, 753 (2011).

${ }^{5}$ F. Y. Bruno, J. Garcia-Barriocanal, M. Varela, N. M. Nemes, P. Thakur, J. C. Cezar, N. B. Brookes, A. Rivera-Calzada, M. Garcia-Hernandez, C. Leon, S. Okamoto, S. J. Pennycook, and J. Santamaria, Phys. Rev. Lett. 106, 147205 (2011).

${ }^{6}$ H. Lu, T. A. George, Y. Wang, I. Ketsman, J. D. Burton, C. W. Bark, S. Ryu, D. J. Kim, J. Wang, C. Binek, P. A. Dowben, A. Sokolov, C. B. Eom, E. Y. Tsymbal, and A. Gruverman, Appl. Phys. Lett. 100, 232904 (2012).

${ }^{7}$ J. D. Burton and E. Y. Tsymbal, Phys. Rev. B 80, 174406 (2009).

${ }^{8}$ J. D. Burton and E. Y. Tsymbal, Phys. Rev. Lett. 106, 157203 (2011).

${ }^{9}$ S. Dong, X. Zhang, R. Yu, J. M. Liu, and E. Dagotto, Phys. Rev. B 84, 155117 (2011).

${ }^{10}$ W. Eerestein, N. D. Mathur, and J. F. Scott, Nature 442, 759 (2006).

${ }^{11}$ W. Eerestein, M. Wiora, J. L. Prieto, J. F. Scott, and N. D. Mathur, Nat. Mater. 6, 348 (2007).

${ }^{12}$ M. K. Lee, T. K. Nath, C. B. Eom, M. C. Smoak, and F. Tsui, Appl. Phys. Lett. 77, 3547 (2000).

${ }^{13}$ D. Dale, A. Fleet, J. D. Brock, and Y. Suzuki, Appl. Phys. Lett. 82, 3725 (2003).

${ }^{14}$ H. F. Tian, T. L. Qu, L. B. Luo, J. J. Yang, S. M. Guo, H. Y. Zhang, Y. G. Zhao, and J. Q. Li, Appl. Phys. Lett. 92, 063507 (2008).
${ }^{15}$ F. D. Czeschka, S. Geprägs, M. Opel, S. T. B. Goennenwein, and R. Gross, Appl. Phys. Lett. 95, 062508 (2009).

${ }^{16}$ G. E. Sterbinsky, B. W. Wessels, J. W. Kim, E. Karapetrova, P. J. Ryan, and D. J. Keavney, Appl. Phys. Lett. 96, 092510 (2010).

${ }^{17}$ T. H. E. Lahtinen, J. O. Tuomi, and S. van Dijken, Adv. Mater. 23, 3187 (2011).

${ }^{18}$ A. Alberca, N. M. Nemes, F. J. Mompean, N. Biskup, A. de Andres, C. Munuera, J. Tornos, C. Leon, A. Hernando, P. Ferrer, G. R. Castro, J. Santamaria, and M. Garcia-Hernandez, Phys. Rev. B 84, 134402 (2011).

${ }^{19}$ Y. Tomioka, A. Asamitsu, and Y. Tokura, Phys. Rev. B 63, 024421 (2000).

${ }^{20}$ M. García-Hernández, A. Mellergård, F. J. Mompean, D. Sánchez, A. de Andrés, R. L. McGreevy, and J. L. Martínez, Phys. Rev. B 68, 094411 (2003).

${ }^{21}$ E. Dagotto, Nanoscale Phase Separation and Colossal Magnetoresistance (Springer, Berlin, 2003).

${ }^{22}$ N. M. Nemes, M. Garcia-Hernandez, Z. Szatmari, T. Feher, F. Simon, C. Miller, J. Garcia-Barriocanal, F. Bruno, C. Visani, V. Pena, Z. Sefrioui, C. Leon, and J. Santamaria, IEEE Trans. Magn. 44, 2926 (2008)

${ }^{23}$ Y. Yoshimura, M. Morioka, A. Kojima, N. Tokunaga, T. Koganezawa, and K. Tozaki, Phys. Lett. A 367, 394 (2007).

${ }^{24}$ D. S. Keeble and P. A. Thomas, J. Appl. Cryst. 42, 480 (2009).

${ }^{25}$ G. H. Kwei, A. C. Lawson, S. J. L. Billinge, and S. W. Cheong, J. Phys. Chem. 97, 2368 (1993).

${ }^{26}$ X. Ren, Nat. Mater. 3, 91 (2004).

${ }^{27}$ Z. Feng and X. Ren, Phys. Rev. B 77, 134115 (2008).

${ }^{28}$ F. Jona and G. Shirane, Ferroelectric Crystals (Pergamon, Oxford, 1962). 
${ }^{29}$ Y. L. Wang, Z. B. He, D. Damjanovic, A. K. Tagantsev, G. C. Deng, and N. Setter, J. Appl. Phys. 110, 014101 (2011).

${ }^{30}$ C. Thiele, K. Dörr, O. Bilani, J. Rödel, and L. Schultz, Phys. Rev. B 75, 054408 (2007).

${ }^{31}$ T. Wu, S. B. Ogale, J. E. Garrison, B. Nagaraj, A. Biswas, Z. Chen, R. L. Greene, R. Ramesh, T. Venkatesan, and A. J. Millis, Phys. Rev. Lett. 86, 5998 (2001).

${ }^{32}$ J. Junquera and P. Ghosez, Nature 422, 506 (2003).

${ }^{33}$ P. Marton, I. Rychetsky, and J. Hlinka, Phys. Rev. B 81, 144125 (2010); 84, 133906(E) (2011).

${ }^{34}$ L. Mihály, D. Talbayer, L. F. Kiss, J. Zhou, T. Fehér, and A. Jánossy, Phys. Rev. B 69, 024414 (2004).
${ }^{35}$ F. Bartolomé, J. Herrero-Albillos, L. M. García, J. Bartolomé, N. Jaouen, and A. Rogalev, J. Appl. Phys. 97, 10 A503 (2005).

${ }^{36}$ A. K. Azad, A. Mellergård, S. G. Eriksson, S. A. Ivanov, S. M. Yunus, F. Lindberg, G. Svensson, and R. Mathieu, Mater. Res. Bull. 40, 1633 (2005).

${ }^{37}$ Z. Fang, I. V. Solovyev, and K. Terakura, Phys. Rev. Lett. 84, 3169 (2000).

${ }^{38}$ A. Biswas, M. Rajeswari, R. C. Srivastava, T. Venkatesan, R. L. Greene, Q. Lu, A. L. de Lozanne, and A. J. Millis, Phys. Rev. B 63, 184424 (2001).

${ }^{39}$ M. Ziese, H. C. Semmelhack, and K. H. Han, Phys. Rev. B 68, 134444 (2003). 